\title{
Factivity Mirrors Interpretation: The Selectional Requirements of Presuppositional Verbs"
}

\author{
Itamar Kastner, NYU \\ itamar@nyu. edu \\ http://www.nyu.edu/projects/itamar
}

To appear in Lingua

\begin{abstract}
Different verbs can take different kinds of arguments. Factive verbs such as remember and forget take clausal complements which are presupposed to be true. In contrast, verbs such as say and think do not presuppose the truth of their complements. I suggest that the complements of presuppositional verbs like remember, forget, admit and deny are actually definite DPs, picking out a discourse referent in the Common Ground. Under this view, factive verbs turn out to be subset of presuppositional verbs, verbs which presuppose the existence of their complement as a proposition in the Common Ground. Factive verbs further require that this proposition be true. It has been established that certain effects arise in clauses embedded by presuppositional verbs: only complements can be extracted from them and argument fronting inside of them is not allowed. I also note that these clauses can have DP pro-forms (which). This stands in opposition to non-presuppositional clauses, where extraction and fronting are possible, and only CP pro-forms ( $a s, s o$ ) are allowed. The DP view allows for a uniform solution to these puzzles; the crucial distinction is whether the matrix verb selects for a definite entity (presuppositional) or for a proposition (non-presuppositional). Going further, I introduce crosslinguistic data showing that the entity/proposition split parallels a split in interpretation between DP and CP complements: a presuppositional DP complement is interpreted like a presupposed entity, while a non-presuppositional CP complement has the semantics of a novel proposition. This way of looking at clausal complements also allows us to account for the behavior of sentential subjects, which have been argued to be both nominal and factive. I flesh out these generalizations and show that they emerge as a natural result in our framework. With sentential subjects as with clausal complements, factivity and presupposition correlate with the syntactic category of the argument. I take this to imply a form-meaning isomorphism in the syntax and semantics with regard to what a verb licenses (DP or CP).
\end{abstract}

\footnotetext{
"I am grateful to Stephanie Harves, Alec Marantz, Anna Szabolcsi and Vera Zu for written comments and advice on previous drafts, and to Dylan Bumford and audiences at TISLR 11 (UCL), the workshop on Clausal Complementation: Current Perspectives (Rutgers), NYU, The CUNY Graduate Center and Queen Mary, University of London for in-depth discussion. I have also benefitted from conversations with Guglielmo Cinque, Kate Davidson, Jane Grimshaw, Kyle Johnson, Manfred Krifka, Tal Linzen, Terje Lohndal, Keir Moulton and Lisa Pearl. Thanks to the consultants who shared their judgments with me; the Greek data are due to Catherine Gkritziou, Maria Kouneli and Fryni Panayidou. Finally, I thank the anonymous reviewers for their many helpful comments. Any remaining errors are my own.
} 


\section{Introduction}

This paper is a study in the kind of arguments that a verb can take. When considering the arguments of a verb, it is tempting to assume that there is a straightforward mapping from syntax to semantics: a DP complement would be an individual whereas a CP would be a proposition. However, since at least Grimshaw (1979) it has been recognized that this view is not always correct: verbs like ask can take a question as their semantic complement but either a DP or a CP as their syntactic complement. Grimshaw (1979) was led to discuss two kinds of selectional requirements on complements, c-selection (syntactic) and s-selection (semantic). Subsequent work has since focused on the question of whether the two could be united under a single licensing requirement. Here, I point out that a direct mapping from syntax to semantics is not only possible for certain verbs but is to be preferred, since it brings along additional empirical benefits.

Work on the syntax-lexical semantics interface has often found it beneficial to divide verbs into classes (e.g. factive and non-factive, Kiparsky \& Kiparsky 1970). We will take the case of PRESUPPOSITIONAL VERBS. These are verbs such as deny and know that presuppose the existence of a discourse referent as their complement. A number of observations have been made about the class of presuppositional verbs, to be elaborated immediately below (or about factive verbs, which form a subset of the larger class). I will argue that these verbs take a DP argument as their direct object. Using the filecard metaphor from the "file change semantics" of Heim (1982, 1983), we may envision a conversation as a file with different filecards, each representing a discourse referent. Introducing a new discourse referent creates a new filecard, whereas making a comment regarding an existing discourse referent involves updating its filecard. All filecards make up the Common Ground, CG. Definite descriptions refer to existing filecards (discourse referents) and indefinite descriptions create new filecards (discourse referents). We will think of entire propositions as filecards.

The idea that presuppositional verbs take definite DPs will initially be motivated on semantic grounds, but taking it seriously will lead to a unified explanation for a range of facts concerning presupposed elements in a range of languages.

Here is a taste of things to come. For a number of decades now it has been observed that clauses introduced by presuppositional verbs pattern differently than clauses introduced by non-presuppositional verbs. First, extraction of complements is allowed from both, (1a)-(2a), while extraction of subjects and adjuncts is allowed from non-presuppositionals only, (1b-c)(2b-c). In other words, presuppositional verbs induce weak islands.

(1) Non-presuppositional (non-factive):

a. What do you think that John stole_?

COMPLEMENT

b. Who do you think_stole the cookies?

SUBJECT

c. Why do you think John stole the cookies_?

ADJUNCT

(2) Presuppositional:

a. What do you remember/deny that John stole__?

COMPLEMENT

b. * Who do you remember/deny stole the cookies?

SUBJECT

c. \# Why do you remember/deny that John stole the cookies

ADJUNCT

In order to explain the weak islandhood effects I adopt the analysis of presuppositional islands in Honcoop (1998). Honcoop argues that a number of islandhood constructions can be explained through semantic well-formedness constraints within a dynamic semantics framework. Importantly, his account of presuppositional islands stipulates an existential requirement of a 
discourse referent. This is no mere stipulation if our system is adopted; instead, Honcoop's semantics can be derived directly from the syntactic structure.

To these examples we add novel data from Hebrew and other languages, showing presuppositional clauses introduced by a determiner. In this case no element can be extracted, (3). This is similar to the case of clauses in English prefaced by the fact that, in which no extraction is possible either (4). These "full" DPs are thus strong islands. We will call them Overt Definite Presuppositionals.

(3) * ma ata zoxer et ze še-dani ganav_? what you remember ACC this COMP-Danny stole

(int. 'What do you remember the fact that Danny stole?')

HEBREW

(4) * What do you remember the fact that John stole _?

ENGLISH

Second, fronting is allowed in non-presuppositional clauses but not in presuppositional clauses:

(5) Non-presuppositional:

a. John thinks that [this book, Mary read].

b. I can assure you that [that film, I don't want to ever see again].

(6) Presuppositional:

a. *John regrets that [this book, Mary read].

b. *John remembers that [this book, Mary read].

Following de Cuba \& Ürögdi (2009) and Haegeman \& Ürögdi (2010a) but sticking to the view of DP presuppositional clauses, I will treat presupposed clauses as "smaller" in some sense, with the covert definite determiner bleeding projection of Topic or Focus nodes in the embedded $\mathrm{CP}$. The fronting ban arises since the fronted elements have no clause-initial landing site.

If the complements of presuppositional verbs are definite descriptions, the prediction is that they should display DP-like properties. We will see that this is correct. Following Ross (1984) and Potts (2002), I demonstrate that the presuppositional verbs know and realize embed both DPs and CPs, whereas non-presuppositional verbs can only embed CPs.

The next step is to extend the discussion of complementation beyond presuppositional verbs and test the predictions of the DP-CP split. The kind of complement selected for, DP or CP, will lead to differences in interpretation. This part of the discussion is limited to some nonpresuppositional verbs, for example explain: depending on whether its complement is a DP or a $\mathrm{CP}$, its interpretation is one of "explaining why" (explain the collapse of the building) or of "saying something by way of explanation" (explain that the building collapsed). This behavior of the verb explain was the subject of work by Pietroski (2000) and Halpert \& Schueler (2013), among others, but our system allows us to generalize to additional verbs and give these differences in interpretation a principled base in the syntax.

Finally, the framework is applied to sentential subjects, which have been argued to be nominal since Rosenbaum (1967) and Ross (1967). Classifying sentential subjects as DPs predicts their extraction effects (the Sentential Subject Constraint) as well as their presupposed and factive nature, a proposal that is corroborated by a new crosslinguistic generalization: the same D that introduces an Overt Definite Presuppositional in languages such as Greek and Hebrew is required in order to introduce a sentential subject. The interpretation of sentential subjects is also predicted correctly.

Analysis-wise, the functional structure within the embedded clause is different for the three types of clauses discussed here: 
- Selected Embedded Non-presuppositionals (think that ...) are CP complements to the verb: $[V P$ V CP].

- Selected Embedded Presuppositionals (regret/deny that ...) are DP complements to the verb, in which a semantically-sensitive determiner $\Delta$ selects $\mathrm{CP}$ :

$[V P \mathrm{~V}[D P \Delta \mathrm{CP}]]$.

- Overt Definite Presuppositionals (the fact that ... in English, or ze ̌̌e-... 'this that ...' in Hebrew and other languages) are full DP complements to the verb, in which an adjunct $\mathrm{CP}$ modifies the noun: $\left.{ }_{V P} \mathrm{~V}\left[{ }_{D P} \mathrm{D}\left[{ }_{N P}\left[{ }_{N P} \mathrm{~N}\right] \mathrm{CP}\right]\right]\right]$. The $\mathrm{CP}$ is not selected as a complement.

The claims made about each construction are summarized in Table 1.

\begin{tabular}{|l|l|c|c|c|c|}
\hline Name & Structure & CP selected & Island & Factive & Special meaning \\
\hline \hline Selected Embedded Non-presup. & {$[\mathrm{V} \mathrm{CP}]$} & yes & no & no & no \\
\hline Selected Embedded Presup. & {$[\mathrm{V}[D P \Delta \mathrm{CP}]]$} & yes & weak & possible & no \\
\hline Overt Definite Presup. & {$[\mathrm{V}[D P \mathrm{D}[N P[N P \mathrm{~N}] \mathrm{CP}]]]$} & no & strong & possible & yes \\
\hline \hline Sentential Subject & {$\left[\left[{ }_{D P} \mathrm{DP} \mathrm{CP}\right] \mathrm{VP}\right]$} & no & strong & possible & yes \\
\hline
\end{tabular}

Table 1: Combinations of V, DP and CP examined in this paper.

I begin in section 2 by explaining my approach to presuppositional clauses and laying out the background for factivity as it is discussed in the literature. I then formalize the proposal as summarized in Table 1 above. The three subsequent sections tackle the empirical puzzles outlined above: the extraction facts (section 3), the fronting facts (section 4) and the as/which distinction (section 5). With this machinery in place we turn to predictions of the DP-CP distinction in other presuppositional and non-presuppositional constructions, as section 6 extends the analysis to cover the interpretation distinctions for presuppositional and non-presuppositional verbs. Section 7 then shows how sentential subjects fit in the picture. Section 8 concludes with take-home messages on presupposition, embedding and selection. Throughout, I use the term presuppositional interchangeably to refer to presuppositional predicates (regretted, denied) or to their clausal complements (that he was late).

\section{Factivity and Presupposition}

Factive predicates are verbs or adjectives that presuppose the truth of their arguments: regret, is significant, makes sense, bothers and so on, as contrasted with non-factive predicates such as say, think, is likely, is possible and appears. Various authors have tried to divide verbs into different classes based on factivity or some notion of referentiality, with the theoretical issue at hand being whether these classes correspond to anything in the grammar. In addition to the factivity/non-factivity split in Kiparsky \& Kiparsky (1970), an influential five-way typology was suggested by Hooper \& Thompson (1973) and a three-way division was discussed by Cattell (1978); it is the latter that we will focus on here. ${ }^{1}$

The notion of verb class is always relativized to some phenomenon: unaccusatives vs unergatives, factives vs semi-factives, verbs of consumption vs others, verbs of emission vs

\footnotetext{
${ }^{1}$ See Hegarty (1990), Melvold (1991) and Sheehan \& Hinzen (2011) for work building on the earlier models, but compare Simons (2007) for a view in which the pragmatics are more important than the actual predicate, and Giannakidou $(1998,1999,2001)$ for a typology which considers the referentiality of predicates in order to answer questions about polarity.
} 
others, etc. This section makes the claim that the relevant distinction for the phenomena addressed in this paper is the presuppositional vs non-presuppositional split, with a factive vs non-factive split as a special case among presuppositional verbs. ${ }^{2}$

With the concept of factivity established, a considerable literature began pointing to certain syntactic effects that were limited to either factive or non-factive environments, to be reframed in what follows as presuppositional or non-presuppositional environments.

\subsection{Presuppositional and Non-presuppositional Verbs}

We will limit our discussion to clausal complements of verbs (as opposed to adjectives, the selectional properties of which are a different matter. See Hartman 2012:36). The literature has mostly centered on factive verbs (Zubizarreta 1982; Adams 1985; Rooryck 1992; Abrusán 2011, 2014), but the more informative class of verbs to consider is "referential" verbs (Haegeman \& Ürögdi 2010a), or presuppositional in our terminology. This is the relevant breakdown, originally proposed to describe adjunct extraction patterns (Cattell 1978; Hegarty 1990):

(7) a. NON-STANCE (factive): regret, know, remember, realize, notice, etc.

b. RESPONSE STANCE: deny, accept, agree, admit, confirm, verify, etc.

c. VOLUNTEERED STANCE: think, suppose, assume, claim, suspect, etc.

It will be shown that NON-STANCE VERBS pattern together with RESPONSE STANCE VERBS to the exclusion of the non-presuppositional VOLUNTEERED STANCE VERBS with regards to the phenomena examined below-extraction (section 3), fronting (section 4), nominalhood (section 5) and interpretation (sections 6 and 7).

I suggest that the difference between non-stance (7a) and response stance verbs (7b) be treated as follows. Both are presuppositional, but the former are also factive. Accordingly, both classes of verbs presuppose the existence of their complement, but only the former presuppose the truth of the clause embedded in their complement. The next subsection exemplifies.

\subsection{Presuppositional and Non-presuppositional Clauses}

In order to recognize the basic difference between the three classes in (7), consider the following examples. A non-presuppositional verb like say can introduce a new idea. A presuppositional verb like deny can only refer to an already-existing notion. A factive (presuppositional) verb like remember can only refer to an already-existing notion which is also true.

(8) a. John said [that the moon was made of kale]. (No one had claimed that before.)

b. Bill denied [that he stole the cookies]. (\# No one claimed that he had stolen them.)

c. \# Bill remembers [that the moon is made of kale]. (\# No one had told him that before.)

Before we formalize the analysis, it is important to note that clauses can be made factive in a number of ways. Some verbs are inherently factive, meaning that their complements cannot be negated:

\footnotetext{
${ }^{2} \mathrm{~A}$ reviewer asks whether factives should be distinguished from semi-factives in this context. Perhaps not: the canonical "semi-factive" discover behaves similarly to the factive verbs discussed in this article. See Simons (2007) and especially Beaver (2010) for skeptical discussion of whether semi-factives even form a separate class, and Sheehan \& Hinzen (2011) for arguments that they do.
} 
(9) a. I thought/claimed/suggested that the building collapsed, but it didn't.

b. \# I regretted/remembered/knew that the building collapsed, but it didn't.

Non-presuppositional clauses can be made factive by prefacing them with the fact. Utterances (10a-b) are non-factive and can be denied, but (10c-d) cannot:

(10) a. I explained [that the building collapsed], but it didn't really.

b. I explained [that the building collapsed], but I was just making an excuse for being late.

c. \# I explained [the fact that the building collapsed], but it didn't really.

d. \# I explained [the fact that the building collapsed], but I was just making up an excuse for being late.

The same can be said for predicates like predict or anticipate, as their presuppositions covary with the form of their complements: $[C P$ that ...] in the (a) examples or $[D P$ the fact that ...] in the (b) examples.

(11) a. I predicted that the building would collapse, but it didn't.

b. \# I predicted the fact that the building would collapse, but it didn't.

(12) a. I anticipated that the enemy would destroy the city, but it didn't.

b. \# I anticipated the fact that the enemy would destroy the city, but it didn't.

It should not come as a surprise that the lexical item fact triggers factivity. Earlier analyses have even suggested that factive clauses are headed by a silent FACT element (Kiparsky \& Kiparsky 1970; Kayne 2008), an idea we will later reject as it cannot account for the extraction or interpretation facts.

But let us now introduce data from Hebrew where factivity is licensed by the proximal demonstrative ze, a functional element rather than a lexical item like fact (Hebrew ze heading an embedded clause is impossible after xašav 'thought' and amar 'said', just like how English the fact that is not preceded by think or say).

(13) a. hu hisbir [še-ha-binyan karas] (aval hu lo be'emet karas) he explained COMP-the-building collapsed but he NEG really collapsed 'He explained that the building collapsed (but it didn't).'
b. hu hisbir et [ze še-ha-binyan karas] (\# aval hu lo be'emet he explained ACC this COMP-the-building collapsed but he NEG really karas) collapsed

'He explained the fact that the building collapsed (\# but it didn't).'

This behavior is not unique to Hebrew: Greek uses the definite article to (Roussou 1992) and Persian uses the proximal demonstrative in (Farudi 2007). In American Sign Language, this presuppositionality is signaled by signing the relevant propositions or individuals in different spatial locations, the ASL equivalent of a determiner (Kastner \& Davidson 2013). Notably, these determiners always seem to be definite or proximal, never indefinite or distal.

We use file change semantics to capture the difference between presuppositional and nonpresuppositional clauses. In this theory, a discourse is conceptualized as a file containing different filecards (Heim 1982, 1983). Each card corresponds to a discourse referent, and these referents make up the conversational Common Ground, CG (Stalnaker 1973, 1974; Lewis 1979). When one of the participants in the conversation brings up a certain individual, both interlocutors look up the relevant filecard. If the speaker makes a comment regarding that individual, the interlocutors update its filecard with the new information. If a speaker introduces 
a new discourse referent, the interlocutors create a new filecard and add it to the file.

Heim analyzes indefinite descriptions as introducing new discourse referents and creating new filecards. Definite descriptions, in contrast, refer to existing discourse referents qua filecards. Making a comment on an existing discourse referent is comparable to writing new information on the referent's filecard. In such a system, there is a fundamental difference between indefinite and definite descriptions, between creating a new filecard and referring to an existing filecard. What I would like to do here is think about entire propositions as discourse referents. In the examples in (8) above, the non-presuppositional verb said creates a new filecard and adds a new discourse referent to the CG, namely the novel claim that the moon is made of kale. This proposition need not have been uttered before. Contrast this with the behavior of denied and remembers in ( $8 \mathrm{~b}-\mathrm{c})$. There, the verb takes as its complement a claim that exists in the CG. Someone had already alleged that Bill stole the cookies, otherwise (8b) would not be felicitious because one does not deny something that has not been alleged yet. Similarly, someone had already told Bill that the moon was made of kale in (8c). It is impossible to remember something than has not been said yet. As Honcoop (1998:167) puts it, verbs like deny "presuppose that their complements express assumptions or claims held by someone possibly other than the speaker which are part of the common ground."

We implement the intuition behind presuppositional verbs selecting discourse referents from the CG by grounding filecards in the syntax: the clausal complement is itself part of a definite DP. In this model, the syntax generates a structure which is interpreted with respect to the discourse by the semantics. This way, Heim's generalization about definite descriptions referring to existing discourse referents still holds. Under our analysis, these clausal complements are DPs which themselves embed CPs, rather than "ordinary" CPs. The difference between factive (and obligatorily presuppositional) verbs and non-factive presuppositional verbs is not a structural one, but a lexical-semantic one: both embed DPs, yet only factives require the proposition embedded within the DP to be true. In contradistinction, non-presuppositional clauses are "ordinary" CPs. There is no reason to treat them as definite, and they may introduce a new discourse referent.

\subsection{The Proposal}

We break the data down into three separate constructions, which we call Selected Embedded Non-presuppositionals, Selected Embedded Presuppositionals and Overt Definite Presuppositionals. The first corresponds to non-presuppositional environments, the second to presuppositional environments with a clausal complement to a presuppositional verb, and the last to presuppositional environments with an overt element such as the fact or Hebrew ze heading the embedded clause. Table 1 is reproduced here to anticipate the discussion.

\begin{tabular}{|l|l|c|c|c|c|}
\hline Name & Structure & CP selected & Island & Factive & Special meaning \\
\hline \hline Selected Embedded Non-presup. & {$[\mathrm{VCP}]$} & yes & no & no & no \\
\hline Selected Embedded Presup. & {$[\mathrm{V}[D P \Delta \mathrm{CP}]]$} & yes & weak & possible & no \\
\hline Overt Definite Presup. & {$[\mathrm{V}[D P \mathrm{D}[N P[N P \mathrm{~N}] \mathrm{CP}]]]$} & no & strong & possible & yes \\
\hline \hline Sentential Subject & $\left.\left[{ }_{D P} \mathrm{DP} \mathrm{CP}\right] \mathrm{VP}\right]$ & no & strong & possible & yes \\
\hline
\end{tabular}

Table 1: Combinations of V, DP and CP examined in this paper.

\subsubsection{Selected Embedded Non-presuppositionals}

This group contains verbs that are not inherently presuppositional, such as think and claim, and which take a clausal complement. Under our analysis, the matrix verb selects for a proposition, 
i.e. a CP following the Canonical Structure Representation of Grimshaw (1981):

(14) Bill thinks that John stole the cookies.

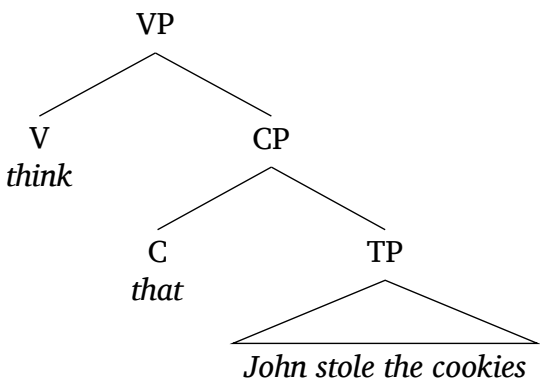

(15) Selected Embedded Non-presuppositionals

- V selects for a proposition, CP.

- They are not presuppositional.

This is not to preclude non-presuppositional verbs from taking DP complements: answer may take a DP (16a) or a CP (16b), but the structure for (16b) will be as in (14) above.

(16) a. The President answered $[D P$ the question].

b. The President answered [ ${ }_{C P}$ that construction will go ahead as planned].

The next construction is the presuppositional counterpart.

\subsubsection{Selected Embedded Presuppositionals}

This group contains predicates whose lexical semantics is inherently presuppositional, such as remember, know, regret and deny. These verbs appear as if they took a clausal complement, but I put forward that this is not actually the case; in my analysis they differ from their nonpresuppositional counterparts in taking a definite DP, the filecard (a discourse referent). The matrix verb subcategorizes for a definite DP, which is interpreted as a definite entity. We use a special symbol for the covert definite determiner, following the covert determiner in Adger \& Quer (2001): $\Delta .^{3}$ This determiner itself selects for a CP (proposition) as its complement.

(17) Bill remembers/denies that John stole the cookies.

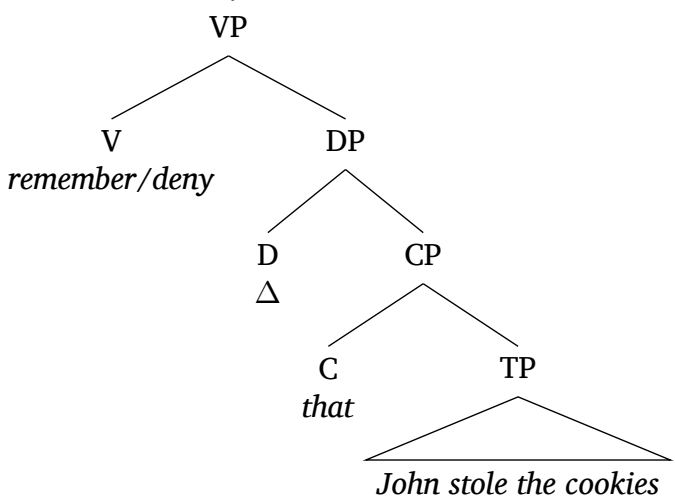

\footnotetext{
${ }^{3}$ The silent determiner is not a new idea in and of itself. In the semantics literature, Pelletier \& Schubert (1989/2003) used a null determiner for mass nouns and Asher (1993:146) proposed a "silent the" to handle possession patterns.
} 
(18) Selected Embedded Presuppositionals are definite elements:

- V selects for a semantically-sensitive definite $\mathrm{D}$, namely $\Delta$. This determiner, in turn, selects for a CP with a presuppositional Force head (see section 4). ${ }^{4}$

- They are presuppositional.

This is not to preclude presuppositional verbs from taking "ordinary" DP complements: know can take a DP (19a) or a clausal complement (19b), but the structure for (19b) will be as in (17) above.

(19) a. The President knew [DP the answer].

b. The President knew ${ }_{D P} \Delta\left[_{C P}\right.$ that construction will go ahead as planned]].

Naturally, presuppositional verbs might also take a DP headed by the indefinite article (John knows a good linguist). Nevertheless, in Selected Embedded Presuppositionals the complement clause is not a "pure" CP but is embedded under $\Delta$.

There is one more structure to consider, one in which a full DP is instantiated.

\subsubsection{Overt Definite Presuppositionals}

This group contains verbs that are followed by a clause headed by an overt determiner. Overt Definite Presuppositionals differ from Selected Embedded Presuppositionals in that the DP selected by the matrix predicate is a full DP with an NP layer (the fact that), a "DP shell" (Takahashi 2010; Hartman 2012). The embedded clause is an adjunct modifying the noun phrase and not a complement, as per Moulton (2015). ${ }^{5}$ Hebrew lexical items have been added beneath the English ones. ${ }^{6}$

(20) Bill remembers the fact/claim that John stole the cookies.

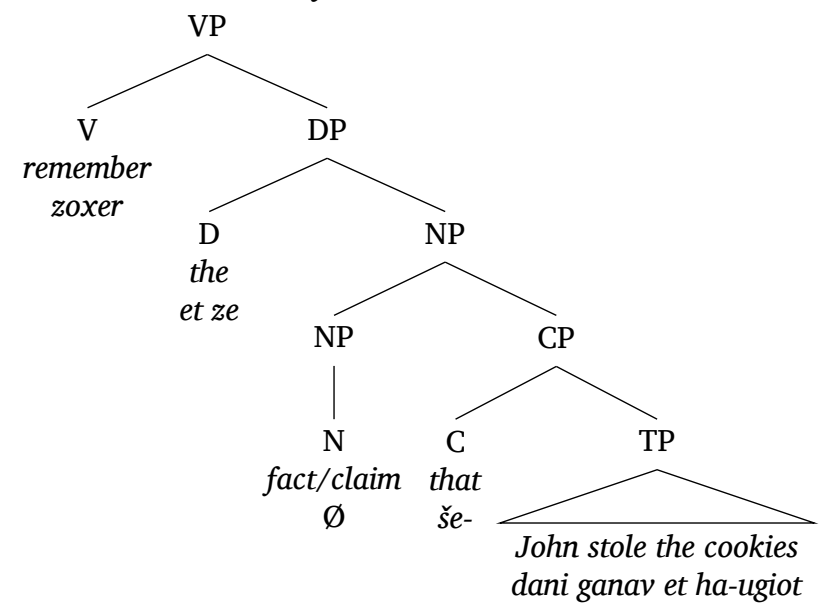

\footnotetext{
${ }^{4}$ For a possible take on the semantics of [ $\Delta$ CP], see Takahashi (2010:356ff14). For discussion of the obligatoriness of C, which we do not go into here, see Sheehan \& Hinzen (2011). On the definiteness of presupposed clauses see Kempson (1975:134) and Melvold (1991).

${ }^{5}$ An anonymous reviewer asks about the argument-adjunct asymmetry in Condition C effects for complements of nouns as discussed by Lebeaux (1988) and Fox (1999). If the CP in (20) is an adjunct, the asymmetry would remain unexplained. However, Moulton (2013:273) provides a reanalysis of the phenomenon, concluding that these CPs are nevertheless adjuncts and that they do bleed Condition C effects in correctly controlled-for environments (Kuno 2004:335):

(i) Which psychiatrist's view that $\mathrm{John}_{i}$ was schizophrenic did he $\mathrm{e}_{i}$ try to get expunged from the trial records?

${ }^{6}$ For simplicity, I adjoin the accusative definite marker et to the demonstrative ze 'this'. An overt $\mathrm{N}$ is possible in Hebrew, although in that case D is spelled out as ha-ze 'the this' (cf. Shlonsky 2004).
} 


\subsection{Definite DPs or CPs?}

An anonymous reviewer points out that in the proposal put forward by Sheehan \& Hinzen (2011), presuppositional clauses are treated as definite and referential CPs, obviating the need to treat them as DPs and use a covert determiner. The intuition behind their analysis and ours is similar, but there are a number of reasons not to adopt the definite CP approach.

Conceptually, the notion of a definite clause is not clearly defined. CPs do not usually take morphological definiteness marking as DPs do, nor is the assumption of definite CPs commonplace. A similar question concerns referentiality: what does it mean for a clause to be referential? A more comprehensive theory of referential CPs would likely rely on evidence from question CPss, subjunctive CPs, and so on, in both embedded and matrix contexts.

Additionally, in terms of implementation, a proposal in which only DPs can be $[ \pm$ Def $]$ is more constrained than one in which both CPs and DPs can be $[ \pm$ Def $]$.

On the empirical side, this paper addresses two phenomena that cannot be accounted for by the system of Sheehan \& Hinzen (2011). In the next section we will analyze extraction patterns from weak islands. Sheehan \& Hinzen (2011) lay out a theory with six classes of predicates, depending on whether their complement CPs are definite or indefinite on the one hand, and strongly assertive, weakly assertive or not assertive on the other. One upshot of this breakdown is that doubt, deny and be likely are considered to embed indefinite CPs and not induce island effects. However, these kind of predicates-presuppositional predicates-are weak islands.

As for the second empirical phenomenon distinguishing the two theories, I show in Section 5 that presuppositional clauses have the distribution of DPs, not of CPs. Section 7 makes similar claims about sentential subjects. These generalizations would be unaccounted for if presuppositional clauses must be CPs.

The opposite question might also be asked: if SEPs are definite DPs, why not treat SENs as indefinite DPs? Recall that there are two reasons for this. SEPs are referential, which we achieve in the syntax by making them definite. SENs are not referential, so there is no need to stipulate a [-Def] feature to derive non-referentiality. In addition, and as just mentioned, sections 5 and 7 provide distributional evidence for treating SEPs as DPs and SENs as CPs.

The main contribution of this paper, then, lies in clearly delineating the syntax which feeds the semantics of embedded clauses. With this machinery in place, we will now tackle the three puzzles mentioned earlier: extraction effects, fronting effects and the as/which contrast.

\section{Extraction and Islandhood}

There are two kinds of extraction facts to be accounted for. Movement out of Selected Embedded Presuppositionals is restricted: only certain complements can be extracted, not subjects or adjuncts. This is the weak islandhood puzzle, which we will solve by showing that SEPs provide syntactic grounding for a semantic intervention account. I have also introduced Overt Definite Presuppositionals. These are strong islands that prohibit any movement. We will account for this behavior by showing that Overt Definite Presuppositionals are full DPs, thereby reducing their islandhood to the Complex NP Constraint.

\subsection{Weak Islands: Extraction from Selected Embedded Presuppositionals}

Extraction from non-presuppositional predicates like think is possible in ways that extraction from presuppositional predicates like remember is not, as can be seen in (21)-(22), adapted 
from Hegarty (1990), Basse (2008) and Haegeman \& Ürögdi (2010a). Only complements can be moved: direct objects or objects of prepositions.

(21) Extraction from non-presuppositionals is generally allowed:

a. What do you think (that) John stole _ ?

COMPLEMENT

b. Where do you think John came from _ ?

COMPLEMENT

c. Who do you think _ stole the cookies?

SUBJECT

d. Why do you think that John stole the cookies

ADJUNCT

(22) Only complements can be extracted from presuppositionals:

a. What do you remember/deny that John stole _ ?

b. Where do you remember/deny that John came from _ ?

c. *Who do you remember/deny_ stole the cookies?

d. \# Why do you remember/deny that John stole the cookies _ $?^{7}$

Generally speaking, even extraction of complements from presuppositionals may be degraded (examples adapted from Kluender \& Kutas 1993:628):

(23) a. ?What did you figure out you will say to your boss in the meeting?

b. ? Who did the senator figure out that they discovered ? ?

(24) a. ?What did you figure out that you should tell your boss about _ before the meeting?

b. ?Who did the senator figure out that they had discovered something about _ in the press room?

It is important to note that the ungrammaticality of (22c) is not due to some conspiracy in which the complementizer is obligatory (Melvold 1991) but is disallowed in accordance with the that-trace effect. This effect can arguably be ameliorated by the right kind of adverbial (Culicover 1993), but the relevant repair strategies do not render the example acceptable:

(25) *Who do you remember/deny/agree that \{undoubtedly/just yesterday/by your recollection\} stole the cookies?

The repair strategies discussed by Kandybowicz (2006) do not help either; the examples remain ungrammatical, and this pattern persists in the other languages mentioned here as well. I discuss the crosslinguistic data in section 3.1.1 and propose an analysis in section 3.1.2.

\subsubsection{The facts}

Extraction from non-presuppositionals is allowed in Hebrew as in English:

(26) Hebrew declaratives (baseline example):

ani xošev/makxiš/zoxer še-dani ganav et ha-ugiot (ki hu haya

I think/deny/remember CoMP-Danny stole ACC the-cookies because he was ra'ev)

hungry

'I think Danny stole the cookies because he was hungry.'

\footnotetext{
${ }^{7}$ Ungrammatical on the intended "low" reading.
} 
(27) Hebrew extraction from non-presuppositionals: ${ }^{8}$

a. ma ata xošev še-dani ganav_?

what you think CoMP-Danny stole

'What do you think that Danny stole?'

COMPLEMENT

b. mi ata xošev (še-) _ ganav et ha-ugiot?

who you think COMP- stole ACC the-cookies

'Who do you think stole the cookies?'

SUBJECT

c. lama ata xošev še-dani ganav et ha-ugiot__?

why you think COMP-Danny stole ACC the-cookies

'Why do you think Danny stole the cookies?'

ADJUNCT

Extraction from Selected Embedded Presuppositionals is only allowed for complements:

(28) Hebrew extraction from presuppositionals:

a. ma ata makxiš/zoxer še-dani ganav_?

what you deny/remember CoMP-Danny stole

'What do you remember that Danny stole?'

COMPLEMENT

b. *?mi ata makxiš/zoxer (̌̌e-) _ ganav et ha-ugiot?

who you deny/remember COMP- stole ACC the-cookies

(int. 'Who do you remember stole the cookies?')

SUBJECT

c. \#lama ata makxiš/zoxer še-dani ganav et ha-ugiot__?

why you deny/remember COMP-Danny stole ACC the-cookies

(int. 'Why do you remember that Danny stole the cookies?')

ADJUNCT

A similar pattern obtains in Greek, but we will not review the Greek facts here due to an added complication: the language has two complementizers, "factive" $p u$ and "non-factive" oti, which interact with the embedding structure in ways that are not yet fully understood and which lie beyond the scope of this paper. ${ }^{9}$

Elements that block a certain extraction are weak islands (for an overview see Szabolcsi \& den Dikken 1999). Those elements that can be extracted from weak islands are usually complements, rather than specifiers. ${ }^{10}$ Our structure for Selected Embedded Presuppositionals illustrates the extraction facts without providing an explanation yet:

(29) What do you remember/deny that John stole _?

$\left[\mathrm{CP}\right.$ what $_{i} \ldots$ [VP remember/deny [DP $\Delta\left[\right.$ CP $_{\text {That }}$ that [TP John stole what $\left.\left.\left.\left.{ }_{i}\right]\right]\right]\right]$

\footnotetext{
${ }^{8}$ Extraction of a subject across an overt complementizer is more permissive in Hebrew than in English (Doron 1983; Shlonsky 1988).

${ }^{9}$ For example, some speakers allow extraction of complements out of presuppositional islands regardless of the complementizer, some allow extraction only with oti and some disprefer it completely. For all speakers, the subjunctive particle na can be used to introduce a subjunctive clausal complement, out of which all extraction is possible. $\mathrm{Na}$ is obligatory for some predicates (e.g. control verbs) and optional with others. In addition, there might be a further subdivision in that lipate 'regrets' patterns differently from thimate 'remembers' in terms of whether or not their complements can be negated. For discussion of the complementizers, see Roussou (1992, 2010). For related discussion of factivity, see e.g. Giannakidou (1998).

${ }^{10}$ Complements extract more easily than specifiers even in strong islands such as the Coordinate Structure Constraint of Ross (1967:168):
}

(i) What did you [[go to the store] and [buy __ ] ]?

(Hofmeister \& Sag 2010:370) The traditional analyses of extraction rely on the complement being properly governed, reducing its behavior as described by the Condition on Extraction Domains (Huang 1982) to the Empty Category Principle. We will not attempt a Minimalist rethinking of Subjacency here, though see Müller (2010) and references therein for a few approaches. 
(30) * Who do you remember/deny (that) stole the cookies?

[CP $\mathrm{who}_{i} \ldots$ [VP remember/deny [DP $\Delta$ [CP $\mathrm{CO}_{i}$ that [TP $\mathrm{TP}_{\imath}$ stole the cookies ]]]]]

(31)\# Why do you remember/deny (that) John stole the cookies ?

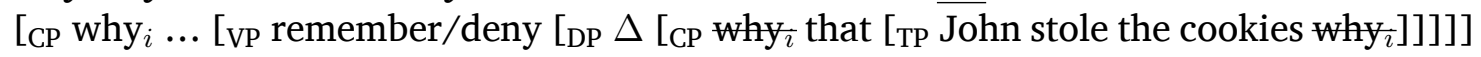
This is not to say that any complement can be extracted from a presuppositional island. Rather, Selected Embedded Presuppositionals pattern like other weak islands with regards to the kind of element that can be extracted, depending on other elements in the clause, (33)-(34). The following examples are adapted from Szabolcsi \& Zwarts (1993:241,271).

(32) Complement extraction permitted ("simple" weak island):

a. Which man did you see _ ?

b. Which man do you regret/deny that you saw ?

(33) Measure phrases with negation as an island, banning complement extraction:

a. "How much milk didn't you drink _ ?

b. *How much milk don't you regret/deny that John drank ?

(34) 'One time only' predicates as an island, banning complement extraction:

a. Which relatives do you regret that you showed the ring to _ ?

b. *Which relatives do you regret that you got this ring from ?

It has thus been the general view that presuppositional verbs are weak islands and that weak islands are best analyzed as a semantic phenomenon rather than a syntactic one, as discussed in a number of works contrasting the two approaches (Szabolcsi \& Zwarts 1993; Szabolcsi \& den Dikken 1999; Szabolcsi 2006; Abrusán 2014). The question is why presuppositional verbs induce weak islands. To answer this, I will invoke the account proposed in Honcoop (1998) and show how it builds directly on the syntactic scaffolding given above.

\subsubsection{Dynamic excursions}

The question in connection with weak islands is how to distinguish between presuppositional and non-presuppositional attitude verbs. Szabolcsi \& Zwarts (1993) proposed an explanation which Honcoop (1998) revises and fleshes out. Honcoop's theory of weak islands rests on the observation that the interveners that induce weak islands (negation, quantifiers and so on) are generally the same as those that block cross-sentential anaphora (he) to an indefinite (a man):

(35) a. John saw a $\operatorname{man}_{i} \cdot \mathrm{He}_{i}$ whistled.

b. *John didn't see a $\operatorname{man}_{i}$. $\mathrm{He}_{i}$ whistled.

Honcoop makes use of this observation by arguing that extraction of expressions sensitive to weak islands crucially involves a semantic operation (Existential Disclosure of Dekker 1993) whose mechanics has such an anaphoric component. When this operation is blocked, so is extraction; see Honcoop (1998) for elaboration, and Szabolcsi (2006) for a brief summary.

But Honcoop observes that in the case of attitude verbs such as the ones discussed in our paper, the classes that induce weak islands and those that block cross-sentential anaphora do not coincide. Specifically, volunteered stance verbs (36a) block cross-sentential anaphora and do not induce weak islands; while factives (36c) do not block cross-sentential anaphora and do induce weak islands (Honcoop 1998:168). 
(36) a. *John thought he met a photomodel $i$ yesterday. She ${ }_{i}$ smiled at him.

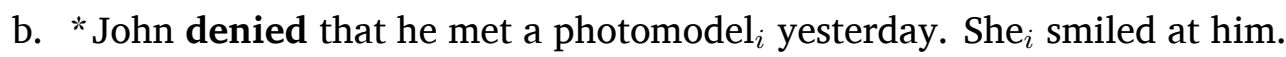

c. John is happy that he met a nice $\operatorname{girl}_{i}$ yesterday. She $e_{i}$ smiled at him. This problem is resolved by referring to the idea that complements of volunteered-stance verbs introduce new, non-presupposed propositional discourse referents (much like indefinites do), whereas the complements of response-stance and non-stance predicates add further information to old, presupposed propositional discourse referents (much like definites do). These two kinds of referents support different kinds of cross-sentential anaphora (Groenendijk \& Stokhof 1991). Only the non-presupposed, "indefinite" propositional referent supports the kind of anaphora that successfully feeds Existential Disclosure and thus facilitates the extraction of expressions sensitive to weak islands. ${ }^{11}$

Honcoop argues that the grammatical cases involving volunteered-stance verbs (think, claim), should be assimilated to modal subordination (37), with propositional discourse referents playing the role of individual discourse referents (Honcoop 1998:171).

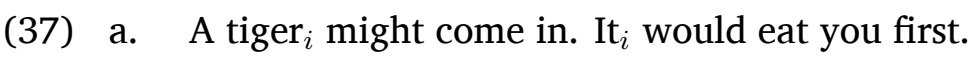

b. John thinks he has a dollar ${ }_{i}$ in his wallet. He wants to give it $i_{i}$ to the beggar.

In such cases the second sentence in each example is modally subordinate to the first sentence (Roberts 1989). The semantics suggested by Groenendijk \& Stokhof (1989:38) for (37a) can be paraphrased as follows: the first modal introduces a discourse referent $i$. This discourse referent is picked up as an antecedent by the second modal and is used as its restrictor, (38).

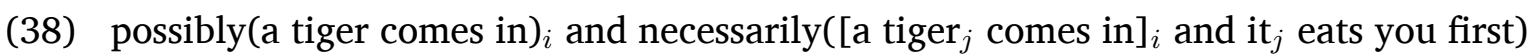
Honcoop's intuition is that the same thing is happening with operators such as think; they, too, introduce a discourse referent.

In contrast, he argues that the presupposed, "definite" propositional referents, such as complements of be happy and regret, support E-type anaphora as in Heim (1992), which do not feed Existential Disclosure. For details, see Honcoop (1998:ch. 4.6.4.1).

To sum up, Honcoop (1998) attempted to equate weak islands with constraints on interclausal binding of indefinites in dynamic semantics. Ultimately, this is a semantic account. For this to work with presuppositional islands, he needed to assume that presuppositional verbs do not introduce a new discourse referent as their complement. These verbs thus serve as interveners for the binding of an anaphor. Non-presuppositional verbs do not face this problem since their new filecard can be seen as an indefinite that binds a cross-sentential anaphor. Honcoop (1998:179) himself invoked the analogy to definite and indefinite descriptions, although he did not go so far as to postulate a definite DP in the syntax. His account is completely asyntactic; our account gives his semantic machinery a syntactic grounding, creating discourse referents for the semantics to manipulate and enabling a clearer mapping from syntax to semantics in general. I will now consider a possible alternative before proceeding to strong islands.

\subsubsection{An alternative: Contrary islands}

Recently, Abrusán $(2011,2014$ ) has developed a system that seeks to explain presuppositional and negative islands in terms of the contradictions that might arise during interpretation. Take for example her treatment of "one-time-only" predicates like get. These predicates induce island effects under factives, unlike their iterable counterparts such as show (data and judgments

\footnotetext{
${ }^{11}$ An anonymous reviewer asks how come objects can nevertheless be extracted from weak islands. I suspect that this is because complements introduce new discourse referents (Irwin 2012), while subjects and adjuncts do not. New discourse referents are indefinites which can be bound.
} 
from Abrusán 2011:277, and cf. (34)):

(39) a. To whom do you regret having shown this letter?

b. *From whom do you regret having gotten this letter?

Example (39a) is unproblematic, since it presupposes that you have shown the letter to more than one person. ${ }^{12}$ It is logically possible to show a letter to more than one person, so (39a) is fine. But if you are presupposed to get a certain letter from more than one person at the same time, that is impossible. This is why (39b) is bad.

The problem with this account is that it does not extend easily from factive verbs as in (39) to response stance (presuppositional) verbs. For factive verbs every individual holds the belief expressed by the embedded clause, since the belief is true no matter who expresses it. But for response stance verbs it is enough that one individual holds the belief; it may not actually be true for everyone. Abrusán (2011:291-292) tackles this challenge head-on with the following example, her (98), cited here verbatim (see also Abrusán 2014:79):

(40) Context: Peter, Fred and Mark and their wives. Each of Peter, Fred, and Mark believe that John slept with their wives (and only their wives).

Which of these three women did Bill deny/admit that John slept with?

As she puts it, "the existential presupposition of the alternative answers can be satisfied by different individuals in the context" (Abrusán 2011:292). But if that were the case, then utterances like the following should be allowed, contrary to fact:

(41) *How did Bill deny/admit/verify that John fixed the car?

(Abrusán 2011:292)

This issue arises because the system in Abrusán (2011, 2014) needs a certain individual to project the presupposition. That allows for (40). However, that wrongly predicts that (41) should be fine. Our account in effect projects the presupposition already in the syntax. It is handed off to the interpretative component, at which point the system developed by Honcoop (1998) kicks in and makes the right predictions.

Before wrapping up weak islands, an anonymous reviewer asks whether evidence from sluicing can be adduced for a syntactic analysis of presuppositional islands. Specifically, if an island effect can be remedied by deletion, then perhaps there was a syntactic reason for the island effect after all (Merchant 2001). Although this is an interesting idea, the data do not seem to support it: SEPs are still ungrammatical under sluicing (42a) and SENs grammatical (42b).

(42) a. *? John denied that someone saw Mary, but I don't remember who $\langle$ John denied saw Mary $\rangle$.

b. John thinks that someone saw Mary, but I don't remember who $\langle$ John thinks that saw Mary $\rangle$.

Nevertheless, it could be interesting to see if presuppositional islands could help adjudicate down the road between approaches to sluicing that require internal syntactic structure (Merchant 2001) and those that do not (Barker 2013).

\subsection{Strong Islands: Extraction from Overt Definite Presuppositionals}

Let us add the other class of presuppositional clauses to the island mix. These are clauses that are prefaced by an overt DP; I dubbed them Overt Definite Presuppositionals since they are prefaced by the overt string the fact that in English but by an overt determiner in various other languages. No extraction is possible from them:

\footnotetext{
${ }^{12}$ An anonymous reviewer challenges this presupposition, and I am inclined to agree: (39a) is fine with only one person being shown the letter.
} 
(43) ENGLISH

a. *What do you remember the fact/claim that John stole _ ?

b. * Who do you remember the fact/claim that_stole the cookies?

c. \# Why do you remember the fact/claim that John stole the cookies ?

(44) HEBREW, repeated from (3)

a. *ma ata zoxer et ze še-dani ganav_?

what you remember ACC this COMP-Danny stole

(int. 'What do you remember the fact that Danny stole?')

b. *mi ata zoxer et ze še-_ ganav et ha-ugiot?

who you remember ACC this COMP stole ACC the-cookies

(int. 'Who do you remember the fact that stole the cookies?')

c. \#lama ata zoxer et ze še-dani ganav et ha-ugiot _ ?

why you remember ACC this COMP-Danny stole ACC the-cookies

(int. 'Why do you remember the fact that Danny stole the cookies?')

Under our analysis, the embedded CP is adjoined to a noun inside a DP. The tree in (45) is repeated from (20).

(45) Bill remembers the fact/claim that John stole the cookies.

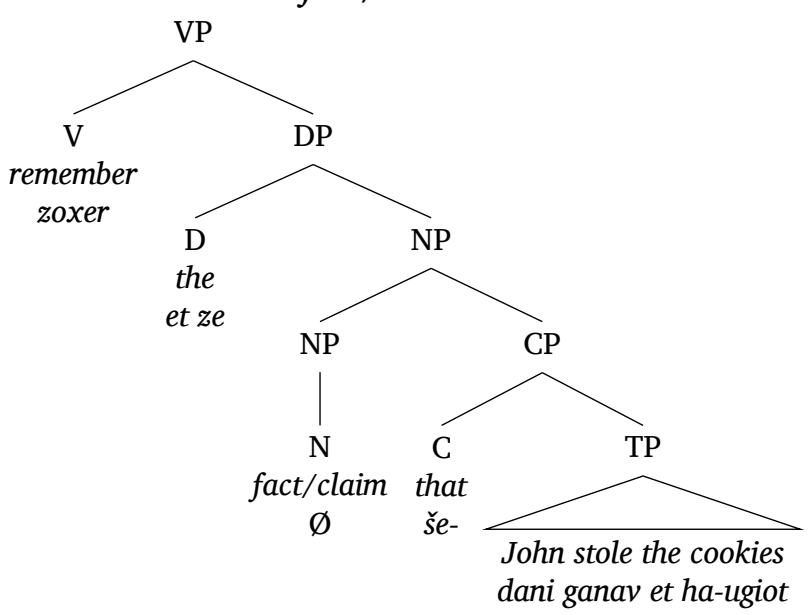

As is well known, extraction from an adjoined clause or a Complex NP is blocked (Ross 1967). This is the situation we are faced with here: none of the elements in the embedded clause can be extracted, since they are part of an adjunct clause/complex NP. ${ }^{13}$

\section{Fronting}

Another phenomenon which has been brought up in the context of factivity, referentiality and presupposition is argument fronting. Fronting is taken here as representative of Main Clause

\footnotetext{
${ }^{13}$ This suggests the following emergent typology of islands:

1. Indefinite $\mathrm{D}+\mathrm{N}$ (indefinite $\mathrm{DP}$ ): weak island.

2. Definite D + N ("full", definite DP): strong island.

3. Definite D with no N (Selected Embedded Presuppositional): weak island.
} 
Phenomena, a topic of much work in the earlier days of transformational grammar (Emonds 1970; Hooper \& Thompson 1973; Green 1976; see Heycock 2006 for a recent review). The question is why fronting is generally allowed in non-presuppositionals but disallowed in presuppositionals (Maki et al. 1999; Basse 2008; Bentzen 2010; Haegeman \& Ürögdi 2010a:112).

(46) Argument fronting in non-presuppositionals, grammatical:

a. John thinks that [this book, Mary read].

b. I can assure you that [that film, I don't want to ever see again].

c. That film, I don't ever want to see again.

(47) Argument fronting in presuppositionals, ungrammatical: ${ }^{14}$

a. *John regrets/denies that [this book, Mary read].

b. *John regretted/denied that [Gone with the wind he never went to see].

While not all speakers agree that the judgments are as clear-cut, speakers do find a contrast in acceptability between the likes of (46) and (47). Additional examples can be found in the works cited above. ${ }^{15}$

In an important early study of Main Clause Phenomena, Hooper \& Thompson (1973) suggested that ungrammaticality arises in clauses that do not make an assertion: "emphasis would be unacceptable in clauses that are not asserted, e.g. embedded clauses which are presupposed" (Hooper \& Thompson 1973:472).

The strong form of this semantic-pragmatic hypothesis has since been challenged (Green 1976; Heycock 2006; Jiménez-Fernández \& Miyagawa 2014): example (47) presents a nonasserted embedded clause with a fronted element, while example (48) shows the presuppositional verb regret, a non-assertive verb, embedding a cleft (another form of emphasis).

(47) I get very upset if I go into my sewing room, and out of the closet pops

your boyfriend.

(Green 1976:390)

(48) We regretted that [it was precisely this book that had been destroyed].

(Heycock 2006)

Although a strong semantic hypothesis like that of Hooper \& Thompson (1973) can be ruled out, the idea is not without merit. Pointing out something that already exists is arguably a limited kind of conversational move. But unlike this earlier work, we need not say that presuppositional utterances are not conversational moves at all. In our solution, a definite structure generated by the syntax feeds semantic effects, in this case topicalization. To do this we must first set up a system in which a matrix verb can place requirements on the embedded clause. I will borrow two components from Adger \& Quer (2001) to this end. The first is the interaction of embedding $\mathrm{V}$, embedded $\mathrm{D}$ and embedded $\mathrm{C}$. The second is the notation for said D.

\subsection{Selection in Selected Embedded Presuppositionals}

What is the nature of the relationship between the verb, the determiner $\Delta$ and C? We say that $\Delta$ requires a CP complement, but what does such a relationship between a determiner and a

\footnotetext{
${ }^{14}$ Surprisingly, know seems less prone to MCP effects:

(i) ? John knows that [this book, Mary read].

Perhaps this might have to do with the high lexical frequency of know.

${ }^{15}$ In order to keep the discussion succinct, I limit myself to English. Preliminary investigation indicates that Hebrew patterns similarly; for an initial take on MCP effects in Hebrew see Shlonsky (2010), cited in Haegeman (2012).
} 
complementizer entail? We will adopt an answer from the work of Adger \& Quer (2001) and see that implementing it in our theory gives us the right kind of control over the left periphery of the embedded clause: the presuppositional verb selects a presuppositional determiner, which in turn selects a C/Force (or Fin) that constrains the availability of Topic and Focus in its clause.

Consider our classification of predicates. We have maintained that presuppositional predicates embed a definite description which refers to a discourse referent in the CG. The definiteness in the definite description is the result of an embedded definite determiner that we label $\Delta$. In other words, $\Delta$ is a definite $\mathrm{D}$ that picks out a unique proposition.

The relevance of Adger \& Quer (2001) lies in that it presents a formal system for reading semantic effects off the syntax of embedded clauses. Adger \& Quer investigated what they termed UNSELECTED EMBEDDED QUESTIONS (UEQs), roughly meaning if-clauses embedded under proposition-selecting predicates like tell (in juxtaposition to SELECTED embedded questions that are selected by predicates such as ask). As a result, c-selection and s-selection are both necessary mechanisms. It turns out that whereas whether-clauses are fine with such predicates (49a), UEQs sound odd to some speakers and ungrammatical to others (49b):

(49) a. The bartender told me [whether I was drunk].

b. \% The bartender told me [if I was drunk].

Adger and Quer uncovered two generalizations. One, that UEQs are fine in downward-entailing environments, behaving in effect like polarity sensitive items.

(50) Questions and negation:

a. Did Julie admit/hear/say if/that the bartender was happy?

b. Julie didn't admit/hear/say if/that the bartender was happy.

Two, that certain predicates simply cannot embed UEQs. These are "true-false" predicates (Ginzburg 1995), predicates that "signal the subject's epistemic commitment to the truth or falsity of the embedded proposition" (Adger \& Quer 2001:110) - i.e. a STANCE. Such predicates cannot embed a question since a question has no inherent epistemic commitment. Importantly for our purposes, the choice of complementizer-that or if-depends on the matrix verb. The following examples are adapted from Adger \& Quer (2001:110):

(51) a. Julie claimed/assumed/maintained that/*if the bartender was happy.

b. Did Julie claim/assume/maintain that/*if the bartender was happy?

c. Julie didn't claim/assume/maintain that/*if the bartender was happy.

The two generalizations imply that a relationship holds between the matrix verb and the embedded clause. First, the polarity facts in (50) imply that licensing is involved, since polarity items must be licensed by a higher element. Second, the sensitivity to certain kinds of verbs in (51) implies that selection is involved. Adger \& Quer (2001) analyze these patterns using a semantically sensitive functional head above the CP, namely the determiner $\Delta$. This determiner might be overt in some languages; data from Basque shows that this language has a complementizer-like element sensitive to the type of clause it introduces. This Basque complementizer can be morphologically decomposed into a $\mathrm{D}+\mathrm{C}$ complex, meaning that the combination of a polar determiner and a CP results in a UEQ in Basque (Adger \& Quer 2001:117). The authors extend this idea to English, proposing that in English $\Delta$ is covert but interacts with the matrix predicate above it and with the $\mathrm{C}$ below it (if/whether/that), bridging the two.

This proposal accounts for the way that the meaning of an embedded question interacts with the matrix predicate; in other words, the [V-D-C] spine mediates the relation between the matrix verb and the embedded clause. $\mathrm{V}$ imposes a selectional restriction, selecting the 
polarity-sensitive determiner $\Delta$, which selects for the appropriate C.

(52) Adger \& Quer (2001:118), adapted:

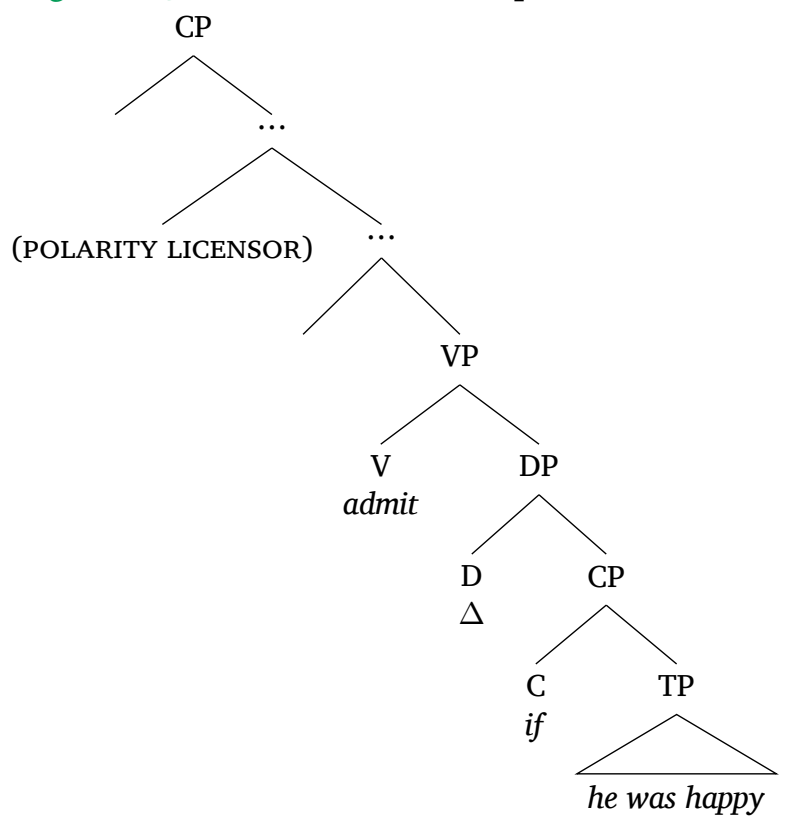

What if the matrix context is not downward-entailing or polarity-sensitive, though, but presuppositional? In this case a $\Delta$ will be licensed that is sensitive to presupposition. This kind of determiner is a definite determiner and that is the account defended here. The verb licenses the semantically-sensitive $\Delta$. The choice of $\mathrm{C}$ is restricted by the semantics of that higher licensor (Adger \& Quer 2001:118). The consequences of C being constrained by presupposition and definiteness will serve to explain the fronting facts. ${ }^{16}$

\subsection{Fronting in Selected Embedded Presuppositionals}

Let us revisit the premise that there is something different about the illocutionary force of presuppositional clauses (Hooper \& Thompson 1973). A number of authors have recently tried to implement this idea in terms of a reduced left periphery, an idea we will follow up on (Basse 2008; de Cuba \& Ürögdi 2010; Haegeman \& Ürögdi 2010a). In his original description of the expanded left periphery, Rizzi suggested that "[I]t is reasonable to assume that the topicfocus system is present in a structure only if "needed", i.e. when a constituent bears topic or focus features to be sanctioned by a Spec-head criterion." (Rizzi 1997:288)

I propose that the Topic and Focus projections are not present in Selected Embedded Presuppositionals, leaving would-be fronted elements with no landing site. Force is supposed to be sensitive to the discourse environment of both the matrix predicate and the embedded predicate-that is the original idea behind the left periphery as mediator between "high" and "low" structure. Force licenses Topic and Focus, so it stands to reason that they are sensitive to certain features on it. Now, the presuppositional embedding verb would carry a feature [F] relevant to presupposition; such a feature has been proposed before, though at this point it is not crucial whether it is [-ASSERT] (de Cuba 2007; Basse 2008), [+ FACTIVE] or [+ REFERENTIAL] (Haegeman \& Ürögdi 2010a). The end result is the same: after V checks this feature on $\Delta$, this definite determiner imposes a selectional requirement on Force similar to that which takes

\footnotetext{
${ }^{16}$ One might then wonder whether the form of $\mathrm{C}$ is constrained by $\Delta$, such that there are presuppositional complementizers and non-presuppositional complementizers. This may be the case in Greek, where one finds "presuppositional" pu alongside "non-presuppositional" oti.
} 
place in UEQs. $\Delta$ licenses a Force with a presuppositional feature, and a presuppositional Force does not license Topic or Focus. ${ }^{17}$

It can now be shown that this account not only prohibits fronting of the kind we want to ban, it also permits examples (47)-(48) seen above and repeated here. These were cases of emphasis in non-asserted clauses, judged to be impossible on a strong semantic-pragmatic view:

(53) I get very upset if [I go into my sewing room, and [out of the closet pops your boyfriend]].

(54) We regretted that [it was precisely this book that had been destroyed].

Example (53) presents a conditional construction. Our analysis has made no predictions here since there is no presuppositional verb to contend with. The system has no reason to ban fronting in this kind of construction.

Example (54) includes a cleft construction, It is $\alpha$ that $\beta$ ( $\alpha$ being the clefted element and $\beta$ the restrictor clause), embedded under the presuppositional verb regret. It could be claimed that it was precisely this book is fronted, a situation that should be banned in our framework. My approach to this issue is simple: there was never any fronting in (54) to begin with.

A common approach to clefts is the "expletive" approach, as in (55). In this case, the clefted element is indeed fronted but in a lower clause. It only raises as high as the complement of $\mathrm{T}$ in the larger embedded clause. The expletive it is base-generated as subject (see Spector 2012 for an instructive overview).

(55) $[T P$ It [is $[C P$ that Mary saw John]]].

$\Rightarrow\left[T P\right.$ It [is $\left[F P \operatorname{John}_{i}\left[C P\right.\right.$ that Mary saw $\left.\left.\left.\left.\mathrm{t}_{i}\right]\right]\right]\right]$.

The clefted element is not fronted to the left periphery of the largest embedded clause, that which is introduced by regret. This analysis of clefts is compatible with our system, which is why it allows example (54) even though it bans fronting.

Before concluding, it is worth considering the relevant class of verbs again: many response stance verbs can take embedded questions as their complements (but not all, e.g. regret cannot). In fact, the class of verbs that can take UEQs is quite heterogenous, at least in terms of presupposition; even tell, a non-presuppositional predicate, can embed a UEQ.

A reviewer correctly points out that UEQs allow fronting of the wh-phrase but still utilize a $\Delta$. Two possible explanations come to mind. One is that perhaps $\Delta$ only licenses Focus, not Topic, in which case the wh-word is free to move through Focus but fronted elements cannot move to Topic. More fine-grained investigation into the kinds of fronting allowed and disallowed would support or falsify this hypothesis, and it is perhaps telling that embedded contrastive focus is allowed in some languages (as a reviewer notes for Greek). A more general possibility is that the $\Delta s$ of UEQs and SEPs are different, for instance differing in definiteness. There might be one determiner for CPs that are UEQs and another for CPs that are declarative presuppositionals, just like English has this for singular proximal DPs and these for plural proximal DPs. I am not arguing that these cases are parallel, simply that figuring out the featural makeup of silent determiners is an important future task for this approach to embedded clauses.

This completes our account of fronting in Selected Embedded Presuppositionals, which uses the same building blocks as our account of extraction. The next empirical phenomenon will utilize the same toolkit, but first we need to discuss why this approach to extraction and fronting is superior to others in the literature.

\footnotetext{
${ }^{17}$ Alternatively, $\Delta$ may select for Fin directly, skipping the Topic and Focus projections and depriving the embedded clause of all illocutionary force. This would be more in line with the referentiality treatment of non-assertive clauses proposed by Haegeman \& Ürögdi (2010a).
} 


\subsection{An alternative: Defective Phases}

Two recent approaches have attempted to give a unified analysis of the extraction and fronting facts. Basse (2008) treated factive clauses as defective phase heads lacking an Edge Feature, namely [ASSERTION], adopting and adapting de Cuba (2007). Without an Edge Feature no element can pass through the phase edge. Fronting is then ruled out, since there is no left periphery to move to.

To explain the extraction facts, Basse suggests that direct objects are probed by the matrix V: its [ACC] feature probes into the embedded clause, finding the object within. The degradedness (in some languages) or ungrammaticality (in others) of extraction from factive clauses is then said to be a result of multiple agreement: first the lower V checks [ACC] on the object and then the matrix $\mathrm{V}$ does the same.

It is unclear, though, why the higher $\mathrm{V}$ must trigger movement of the embedded object rather than checking its feature in situ. Furthermore, this system cannot explain why it is complements rather than objects that can be extracted, in accordance with the Empty Category Principle (Chomsky 1986). Extraction of the complement of V is as good as extraction of the complement of $\mathrm{P}$, meaning that this movement cannot be reduced to accusative case checking.

(56) Repeated from (22):

a. What do you remember [(that) John stole _ ] ?

[V DP]

b. Where do you remember [(that) John came from

[P DP]

\subsection{An alternative: Referentiality Operator}

Haegeman \& Ürögdi (2010a) have developed an analysis in which a referential (i.e. presuppositional) operator intervenes between the left periphery and TP in the embedded clause, ruling out movement. The idea is that leftward movement of a factive element is blocked in a Relativized Minimality way by an operator that has the same factive feature (Rizzi 1990, 2004): the factive element cannot be probed by an element in the left periphery since the operator is found instead. In a way, this is the mirror image of Basse's account; where his embedded clause is [-ASSERT], theirs is [+REFER].

(57) The basics of the referentiality account (Haegeman \& Ürögdi 2010a:137):

a. Non-factive predicates take either a referential or a non-referential clause, while factive predicates can take only referential clauses.

b. Referential clauses denote a proposition with no illocutionary force. A referential clause cannot be an utterance or a speech act unto itself.

c. Non-referential clauses involve a conversational move, i.e. a speech act. Factive verbs cannot embed speech acts because speech acts must contain novel information (de Cuba \& Ürögdi 2009).

Our system has clearly benefited from Haegeman \& Ürögdi's contribution, but I find it preferable to theirs for a number of reasons.

The authors propose that a referential operator intervenes between the left periphery and any material in the embedded clause, ruling out extraction. However, this operator is a theoretical device which does not seem to be overt in any language. Its characterization as a referential operator is also somewhat vague (Bhatt 2010; Kallulli 2010) and its exact position in the clause is still a matter of debate (Aboh 2010; Lipták 2010). It is also there to do the relevant syntactic and semantic work of a functional head without binding any variable as operators normally do. 
Furthermore, the notion of referentiality as used in this theory is not sharply defined, and it is not clear whether or not it is indeed empirically different from factivity or presupposition (Kallulli 2010; Bhatt 2010; Haegeman \& Ürögdi 2010b).

The claim that referential clauses have no illocutionary force whatsoever is debatable. Under this account, a referential clause is comprised of a proposition, made referential by an operator, embedded in illocutionary force, (58a). The result is referential thanks to the referential operator and utterable thanks to Force; in their system, the referential clause is not a DP. Our analysis embeds the presupposed proposition in a DP, resulting in a presuppositional (or "referential") element. This D endows the proposition with referentiality, turning it into a DP along the way, (58b).

(58) a. [Force $\left[\mathrm{Op}_{\text {referential }}\right.$ [proposition]] $\leftrightarrow$ it $_{\text {referential }}$

b. $[\Delta$ [proposition] $] \leftrightarrow \Delta$ it $_{\text {referential }}$

Under the operator theory, fronting and extraction are linked such that a single operator blocks both operations. The theory then makes the prediction that fronting should never be allowed where extraction is not, and vice versa. Let us consider two potential counterexamples.

As noted by Haegeman \& Ürögdi (2010b:242) and Haegeman (2014), the fronting of clitics in Romance (clitic left dislocation, CLLD) is possible in factive clauses, but it is not explained why CLLD might be "special" and not a regular form of fronting. In related work, Haegeman (2010:641) proposes that the fronted clitic should have different features than an ordinary fronted argument but does not specify what these features are.

Another attempt to dissociate fronting from extraction can be carried out in Japanese. As argued for extensively by Jiménez-Fernández \& Miyagawa (2014), fronting is not an MCP in Japanese and is allowed in subordinate clauses. Nevertheless, factive clauses in Japanese are islands for movement (Oshima 2007). Jiménez-Fernández \& Miyagawa (2014) suggest that a discourse feature is inherited from $\mathrm{C}$ by $\mathrm{T}$, so topics only front as far up as Spec,TP, which is lower than the referentiality operator Op. If we attempt to work in this framework, then extraction would still be blocked by Op. It is then necessary to assume that Op inherits the discourse feature, thereby unifying Op with the $\alpha$ head from Miyagawa (2010:69). Such an analysis might "save" the derivation, with fronting of the argument to the specifier of Op (or Spec, $\alpha \mathrm{P})$.

In short, there might be ways to maintain a unified account for extraction and fronting. Nevertheless, such a system still postulates a new functional element (Op), whereas I would argue that $\Delta$ is syntactically and semantically motivated crosslinguistically in a way that the referential operator is not. And so although the prospect of unifying fronting and extraction effects under one referential-operator analysis constitutes a creative approach to factivity effects, we do not adopt it here.

A final point concerns the predictions made by the system. Whether or not it is possible to dissociate fronting from extraction, the operator account has three additional shortcomings when compared to the one developed here: first, it predicts that sentential subjects should be CPs and not DPs (since referential clauses are not DPs in this system). We will see in section 7 that sentential subjects are in fact nominal. Second, it cannot account for differences in interpretation between DPs and CPs. This is the topic of section 6. Lastly, any analysis that posits a null operator which is not a determiner faces the problem of accounting for the DP-like properties of presuppositional clauses, the subject of our next section. 


\section{Clauses as Entities}

If Selected Embedded Non-presuppositionals are CPs and Selected Embedded Presuppositionals are DPs, we would expect the latter to be more "DP-like" than the former. I argue that this is so, the evidence coming from coordination and from anaphoric forms like so and as.

In earlier work it was thought that only phrases of the same kind can be coordinated (Chomsky 1957). Although coordination is no longer considered a watertight diagnostic (Sag et al. 1985), it is suggestive. If we take this test at face value, we find a contrast between the impossible coordination of a CP and DP in non-presuppositionals on the one hand (59a) and what may be analyzed as coordination of two DPs in presuppositionals, on the other (59b).

(59) a. *John claimed [ ${ }_{D P}$ responsibility] and [ $C_{P}$ that the building collapsed].

b. ? John denied ${ }_{D P}$ the allegations] and ${ }_{D P} \Delta$ that the building collapsed].

Instead, let us try to replace the embedded structure with a pro-form. I will use so and as to stand in for CPs; it and which will stand in for DPs. What we expect to see is for nonpresuppositional verbs to be compatible with CP pro-forms but not with DP pro-forms. This is borne out.

To set the stage, note that raising verbs such as seem do not take DP complements, only CP complements. But they can take so as their complement, indicating that so stands in for a CP (Stowell 1987; Moulton 2009:288): ${ }^{18}$

(60) a. It seems $[C P$ so].

b. $\left[{ }_{C P}\right.$ So $]$ it seems.

c. $*[D P$ That/it $]$ seems.

As also patterns with CPs, rather than DPs (Postal 1994; Potts 2002; Moulton 2009:288):

(61) a. Albert boasted/commented/complained [ $C_{P}$ that the results were fantastic].

b. *Albert boasted/commented/complained $\left[_{D P}\right.$ that/it/a belief that the results were fantastic].

c. The results were fantastic, as Albert boasted/commented/complained [ $\left.\mathrm{CP}_{\mathrm{C}}\right]$ ].

We adopt the notion that so and as are pro-forms for clauses in English. The relevant proform for DPs will be which (Potts 2002). Do we see a difference between the two classes of verbs with regards to the kind of pro-forms they license? Yes: only non-presuppositionals license $s o$.

(62) a. John thought/said so.

b. *John remembered/forgot so.

The real counterpart of which is as, not the standalone so. ${ }^{19}$ Potts (2002) discussed the difference between anaphoric as and anaphoric which. Following Ross (1984:258), he showed that know and realize embed both DPs and CPs, either of which can be extracted, (63)-(64).

\footnotetext{
${ }^{18}$ Already Kiparsky \& Kiparsky (1970:166) noticed a noun/clause split for so and it, in that factive verbs prefer a DP to a CP:

(i) a. John supposed [that Bill had done it], and Mary supposed [it/so] too.

b. John regretted [that Bill had done it], and Mary regretted [it/*so] too.

${ }^{19}$ As pointed out by Moulton (2015), so is not identical to that-clauses. For whatever reason, so cannot adjoin to a DP:

(i) a. My belief [that pigs can fly].

b. *My belief [so].
} 
But Potts did not frame this generalization in terms of the verb classes involved. If we consider non-presuppositional verbs, the prediction is that only the CP-form as can be used, not the DP-form which. This is because the complement of the verb in Selected Embedded Nonpresuppositionals is not a DP. Our prediction is borne out in (65)-(66).

(63) a. [Americans should get cheap oil], as the whole world knows

b. [Americans should get cheap oil], which the whole world knows

a. This mist can't last, as Morpho and Hoppy (both) realize

b. This mist can't last, which Morpho and Hoppy (both) realize

(65) a. [Americans should get cheap oil], as the whole world says/claims

b. *[Americans should get cheap oil], which the whole world says/claims

(66) a. This mist can't last, as Morpho and Hoppy (both) claim/announce/think . (CP)

b. *This mist can't last, which Morpho and Hoppy (both) claim/announce/think (DP)

Combining our account of presuppositional verbs with an analysis such as Potts', (63) looks like (67), with the difference in the type of element extracted. If presuppositional verbs take a DP immediately embedding a CP, and non-presuppositional verbs take only a CP, these facts receive an explanation (assuming that a clause can be coreferential with the operator, which is a crucial assumption for any analysis of these facts).

(67) a. [Americans should get cheap oil $]_{i}$, as $\mathrm{Op}_{i}$ the whole world knows $\left[{ }_{D P} \Delta\left[{ }_{C P} \mathbf{t}_{i}\right]\right.$.

b. [Americans should get cheap oil $]_{i}$, which $\mathrm{Op}_{i}$ the whole world knows $\left[{ }_{D P} \mathbf{t}_{i}\right]$.

The observation that verbs like know and realize involve some kind of nominalization of their clausal complement did not escape Potts. He used a nominalization operator $\cap p$ in his analysis, a function from propositions to entities (a type-shifter). Hopefully it is clear by now that $\cap p$ is not necessary: an actual syntactic element, the definite determiner $\Delta$, leads to the same results. The problem with the analysis in Potts (2002) is that it does not constrain where the nominalization operator can be used, save for the restriction that $\cap p$ can only apply to full clauses (Potts 2002:77) and presumably certain verbs. Under our analysis, the use of $\Delta$ is constrained: only certain verbs license it, and crucially these verbs do take nominals as their complements. As in previous cases, what was previously a semantic stipulation can be derived straightforwardly from the syntax.

Potts (2002:71) also claims that "topicalized CPs leave nominal gaps" based on judgments reported in Postal (1994:70), as in (68). One problem here is that the dataset is flawed; the examples are judged ungrammatical by native speakers when confounds such as modals and negation are controlled for, as I show in (69). ${ }^{20}$ But even if Potts' assertion were correct, that might not be the whole story. Topics are necessarily in the CG, by definition. Recall that volunteered stance verbs such as boast create a new filecard - they add a new discourse referent to the CG. What is happening is that these volunteered-stance verbs cannot refer to an existing filecard and so their complements cannot be topicalized (70a). In contrast, presuppositional verbs take a conversational topic (filecard, discourse referent) as their complement and an existing discourse referent may be topicalized (70b).

(68) a. *That the results were fantastic, Albert boasted

b. That Sonia attend the interview, I couldn't insist *(on)

\footnotetext{
${ }^{20}$ I thank an anonymous reviewer for pushing me to revisit the original data, and seven native speaker linguists for their judgments on the data in this section.
} 
(69) a. *That Sonia attend the interview, I insisted (on)

b. *? That the results were fantastic, Albert insisted on

(70) a. *That the results were fantastic, Albert claimed/commented/thought

b. That the results were fantastic, Albert denied/confirmed/knows

\subsection{Interim Summary}

Section 3 presented the extraction puzzle, which we analyzed as extraction from islands: Selected Embedded Presuppositionals are weak islands since the presuppositional verb blocks cross-sentential binding (Honcoop 1998). Overt Definite Presuppositionals do not allow any extraction since they are complex NPs as in Ross (1967), i.e. strong islands.

Section 4 summarized the debate on fronting in factive clauses. Previous work has suggested that the solution cannot be entirely semantic, and our proposal implemented this as a selectional restriction of the embedding verb and the definite determiner.

Section 5 provided additional evidence that Selected Embedded Presuppositionals are DPs whereas Selected Embedded Non-presuppositionals are CPs, based on the pro-forms they license.

With our new typology of embedded clauses in place we have solutions to these three existing puzzles. But we are only halfway through; introducing new data, we can go one step further and ask what influence the selection of a DP or a CP has on the interpretation of the sentence. What predictions does the theory developed here make for the distribution of DPs and CPs writ large? We turn to this next.

\section{Interpretation and Selection}

Now that we have a clearer view of presupposition, we may take a step back and consider the broader picture of embedded clause selection and interpretation. What happens when other verbs take definite DPs - do they become presuppositional? Is there a difference between selecting for an individual and selecting for a proposition? If so, what is the division of labor between the syntax and the lexical semantics? This section investigates a certain set of verbs that can take either DP or CP complements and demonstrates that DP complements can be interpreted differently from CP complements of the same verb.

It has been noted that clausal complements have different interpretations from DP complements, serving more as appositions than actual arguments (Higgins 1972; Stowell 1981; Moulton 2009).

(71) a. I explained $[D P$ the problem $] \approx \mathrm{I}$ EXPLAINED WHY $\mathrm{X}$

b. I explained $[D P$ the procedure $] \approx \mathrm{I}$ EXPLAINED HOW TO DO $\mathrm{X}$

c. I explained $[C P$ that there was a problem $] \approx I$ SAID $X$ AS EXPLANATION

d. I explained $[C P$ that my car broke down] $\approx$ I SAID $x$ AS EXPLANATION

The different meanings of the non-presuppositional verb explain can be brought out by adding different continuations: 
(72) a. He explained [ ${ }_{D P}$ the building's collapse].

...The contractor was a crook, the building supplies were bought cheap and safety regulations were flaunted.

b. He explained [ ${ }_{C P}$ that the building collapsed].

....and that's why the police closed off the street.

I claim here that the meaning of complements varies in a semi-predictable way, depending on the predicate. It varies because the DP-object and the CP-object mean different things. It is predictable because the $\mathrm{CP}$ version will always be this kind of apposition to a general case of the verb. It is semi-predictable because the exact interpretation will depend on the lexical semantics of the verb. I restrict myself to discussion of finite clauses, though it seems that the analysis can be extended to nonfinite CPs just as well. We will flesh out the details and then verify that presupposition reflects the differences in interpretation.

\subsection{Selecting Individuals and Selecting Propositions}

To see how this works let us take explain as a case in point. Our working hypothesis is that a verb can select for a DP or a CP (among other categories), following intensive work on cselection and s-selection (Grimshaw 1979, 1981; Pesetsky 1982, 1992, 1993; Rothstein 1992; Odijk 1997). Some predicates, such as tell, can take either an individual (DP) or a proposition (CP) with no substantial difference in meaning. That is, both sentences in (73) assert that the speaker said something to a third person. In this regard they are truth-conditionally equivalent:

(73) a. I told him $\left[{ }_{D P}\right.$ the time $]$.

'I SAID X'

b. $\approx$ I told him $[C P$ that he was late $]$.

'I SAID X'

The situation is more complex for verbs like explain. The meaning of [explain Obj] covaries with the form of Obj, with a DP object meaning 'explain why' or 'explain how' and a CP object meaning 'say as explanation' (71). The CP object of explain is denotationally similar to the CP object of other verbs like say or wish: it is the content of what is explained, said or wished.

The DP object is free to vary according to the idiosyncrasies of the V-DP relationship, such that different objects entail different readings of the verb as noted by Marantz (1984) and Kratzer (1996) (and see Harley 2014a,b and Anagnostopoulou 2014 for recent discussion in a root-based framework). Returning to the explain example, explaining a problem means saying what the problem consists of or why it happened, whereas explaining the procedure does not mean explaining why the procedure happened but how one follows it.

As noted previously, the CP complement serves more as an apposition than an actual argument, as [explain $\mathrm{CP}$ ] means [give an explanation which is $\mathrm{CP}$ ] (74b).

(74) a. I explained [ $D P$ the problem].

'I said what was the reason for the problem.'

$\approx \llbracket$ I EXPLAINED $\mathrm{x} \rrbracket \approx \lambda$ x.explain $(x)$

b. I explained [ $C P$ that there was a problem].

'I said that there was a problem by way of explanation (for something else).'

$\approx \llbracket I$ SAID X AS EXPLANATION $\rrbracket \approx \lambda x \cdot \operatorname{say}[\exists y \& \operatorname{explanation}(y)$

$\& \operatorname{FCONT}(y)=x]$

I borrow FCONT in (74b) from Moulton (2013:276), where it is given as a function endowing its first argument with propositional content from its second argument. Moulton (2013:274) similarly suggests that the CP sister of a noun identifies the content of said noun. 
The same story holds for other verbs. For instance, the meaning of [observe $\mathrm{CP}]$ is predictable in a way that [observe DP] isn't. The lexical semantics of observe is such that when selecting a proposition (CP), the meaning is always one of seeing something, but when selecting an individual (DP) the meaning is more free to vary. One can observe the Sabbath or observe the patients, with different denotations:

(75) a. I observed $[D P$ the Sabbath $] \approx$ CARRY OUT RITUAL $X$

b. I observed $[D P$ the patients $] \approx \mathrm{WATCH} \mathrm{X}$

c. I observed $\left[{ }_{C P}\right.$ that the patients were angry] $\approx$ MAKE OBSERVATION $\mathrm{X}$

d. I observed $[C P$ that the car broke down] $\approx$ MAKE OBSERVATION $\mathrm{X}$

Or take guess:

(76) a. Guess $[D P$ the killer $] \approx$ FIGURE OUT THE IDENTITY OF $\mathrm{X}$

b. Guess $[D P$ the price $] \approx$ FIGURE OUT THE VALUE OF $\mathrm{X}$

c. Guess $[C P$ that John is the killer $] \approx$ SAY X AS A GUESS

For our next step, note that the DP argument of these verbs can be substituted by a factive [DP CP] with the fact:

(77) He explained [ $D P$ the fact that the building collapsed].

...The contractor was a crook, the building supplies were bought cheap and safety regulations were flaunted.

Crosslinguistic evidence shows that just as in the presuppositional case, this behavior is not due solely to the lexical item fact; Overt Definite Presuppositionals in Hebrew, Greek and Persian (Farudi 2007; Takahashi 2010) have "DP shells" headed by a proximal demonstrative or the definite article. In these languages, too, we see the meaning shift between CPs and DPs. The (b) examples have a 'why' reading.

(78) a. hu hisbir [še-ha-binyan karas]

he explained COMP-the-building collapsed

'He explained that the building collapsed.'

b. hu hisbir et [ze še-ha-binyan karas]

he explained ACC this COMP-the-building collapsed

'He explained the fact that the building collapsed.'

HEBREW

(79) a. $i$ fili $m u m u$ eksijise [oti ipçe to tsai mu] the.F friend.F my to.me explained comp drank the tea my

'My friend explained that she drank my tea.'

b. $i$ fili mu mu eksijise [to oti ipçe to tsai mu]

the.F friend.F my to.me explained the coMP drank the tea my

'My friend explained the fact that she drank my tea.'

GREEK

It can be concluded that [V DP] phrases are able to take on a special meaning while [V CP] phrases cannot, a generalization which is novel in some ways and well-known in others. The fact that explain can take two different kinds of complements was discussed by Pietroski (2000), who limited himself to just this one verb and resorted to thematic roles in order to account for the behavior of the DP and CP arguments. The issue was also noted by Halpert \& Schueler (2013). In other work on clausal complementation, Moulton (2013) invoked FCONT in order to extract the content of nouns such as rumor and belief. Moulton (2012) came close to discussing 
the different meanings of explain and when they arise, but did not talk about that explicitly. Pietroski and Moulton touched the tip of a semantic iceberg. But it is only in the context of a framework that reads the semantics off the syntactic infrastructure, like the one we are developing here, that these intuitions can be generalized to other verbs and languages.

\subsection{Presupposition and Interpretation}

What is predicted for the interpretation of Overt Definite Presuppositionals? We have already seen the answer early on, in (10), expanded on here. The interpretation and presuppositionality of a clause depend on whether the clause is part of a definite DP. A "regular" DP (80) and an Overt Definite Presuppositional (81) are both factive, on top of their special interpretations.

(80) Definite DP, $[V P$ V DP]: special interpretation, factive reading.

a. I explained [ $D_{D P}$ the collapse of the building].

'I explained why the building collapsed.'

b. \# I explained [ $D P$ the collapse of the building], but it didn't really.

(81) Overt Definite Presuppositional, $[D P$ D [NP CP]]: special interpretation, factive reading.

a. I explained [ $D P$ the fact that the building collapsed].

'I explained why the building collapsed.'

b. \# I explained [ $D P$ the fact that the building collapsed], but it didn't really.

(82) Selected Embedded Non-presuppositional, ${ }_{V P}$ V CP]: appositive interpretation, nonpresuppositional reading.

a. I explained [ $C P$ that the building collapsed].

'I said that the building collapsed.'

b. I explained [ ${ }_{C P}$ that the building collapsed], but it didn't really.

What this teaches us is that factivity and interpretation mirror each other: a definite DP is presuppositional and can receive special meaning as in (80)-(81), while a CP is non-presuppositional and does not receive special meaning, (82). Selected Embedded Presuppositionals never receive special meaning because their complement is a silent $\mathrm{D}$ with no $\mathrm{N}$; the $\mathrm{CP}$ is too deeply embedded to influence the meaning of the predicate.

To review, there is good motivation for the idea that embedding predicates can take a DP or a CP complement: some predicates require an individual/DP (hit, deny), some require a proposition/CP (seem) and some require either one (explain, see, observe). Of the latter, the lexical semantics of some is such that there is a difference between CP complements and DP complements. This gives us a consistent view of the semantics: any special meaning will only arise from the interaction of the verbal root and the DP object, with the side effect that the object is presupposed to be a fact. The resulting prediction is twofold: that the meaning of all $\mathrm{CP}$ complements is generated in a predictable way and is in some sense appositive, but that not all DP complements must be interpreted in the same way. This prediction is borne out, helping us to cement the link between interpretation and presupposition.

One last domain remains to be examined, namely, what happens to presupposition and interpretation of clauses in subject position, where the licensing conditions are different. 


\section{Sentential Subjects}

This section makes explicit two common observations about sentential subjects, analyzing them within the framework set up here: that they are nominal and that they are often factive. We will see that sentential subjects are nominal either due to their being in Spec,TP or due to being merged as a DP complement of the verb and undergoing A-movement. As expected by now, nominalhood is predicted to have two correlates: one is presupposition and possible factivity, depending on the specific matrix predicate. The other is special meaning. Both predictions are borne out.

I assume sentential subjects to be "true" subjects in line with the tentative conclusions of Hartman (2012) and Lohndal (to appear). ${ }^{21}$ One implementation of these constructions as subjects generates a null DP in Spec, $\nu \mathrm{P}$ and a coreferential sentential subject in Spec,TP, leaving open the question of how the sentential subject is "made" into a DP (Lohndal 2013:4). That sentential subjects show nominal characteristics is not a new observation by any means, documented by Lees (1960), Rosenbaum (1967) and Ross (1967) and treated more recently by Alrenga (2005), Takahashi (2010) and Hartman (2012:ch. 3).

In this section we will see that sentential subjects are presupposed and usually factive-not a new observation, but one that has not yet been made explicit-with the result that activevoice sentential subjects are simply another kind of Overt Definite Presuppositional. Turning to passive clauses and raising clauses, we will see that their presuppositionality and factivity are predictable from the matrix verb and the syntactic structure.

Once again the connection between selection, presupposition and interpretation will arise: on the one hand, verbs like explain-whose interpretation covaries with the form of their complement-give presuppositional readings even when passivized. On the other hand, raising verbs like seem which select for a CP give non-factive readings when passivized. The same is true of verbs like say whose DP and CP meanings are the same.

A word on the discursive status of subjects is in order first. New discourse referents are usually introduced as objects rather than subjects (Prince 1981; Irwin 2012). A Gricean speaker will refer to a topic already existing in the CG, obeying the Maxim of Relevance. If an utterance does not explicitly mark a topic, the (definite) subject serves as one and so it seems safe to say that subjects are at the very least given. We will thus assume that subjects are discourse referents in the CG.

Since subjects are given in the discourse, I assume that they are interpreted as presupposed. But what we seek to explain is what in the syntax leads them to be interpreted as presupposed in the first place. ${ }^{22}$

\subsection{Sentential Structures}

We have postulated Overt Definite Presuppositional structures for a number of languages. In English, these structures are headed by the fact that, but in Hebrew, Greek, Persian and ASL, they are headed by a single definite determiner. If we take another look at these languages,

\footnotetext{
${ }^{21}$ Sentential subjects have long been at the center of a debate as to whether they are generated as topics or as subjects, or more precisely whether they are generated high in the structure, coreferential with a null operator in argument position (Koster 1978; Alrenga 2005; Takahashi 2010) or in an argument position themselves (Delahunty 1983; Davies \& Dubinsky 2009; Hartman 2012; Haegeman 2014). See Lohndal (to appear) for a summary.

${ }^{22}$ That said, subjects with weak determiners are non-presuppositional, introducing a new discourse referent. For discussion of these see e.g. Diesing (1992:ch. 2). Infinitival sentential subjects might also be non-presupposed, and languages such as Greek allow for subjunctive sentential subjects. These potential counterexamples must be set aside for now. For more on new and old information see Clark \& Haviland (1977) or, for a different take, Irwin (2012). On presupposed subjects see Guéron (1980); on their topichood and givenness, Lohndal (2013).
} 
an interesting pattern emerges. The same D of Overt Definite Presuppositionals must head the sentential subject. For example, Hebrew sentential subjects are obligatorily headed by the determiner ze, just like Hebrew Overt Definite Presuppositionals. The same holds for the other languages; this is not a matter of presupposition but of grammaticality.
[*(ze) še-ha-binyan karas] hiftia oti
this COMP-the-building collapsed surprise me

'(The fact) That the building collapsed surprised me.'

HEBREW

(84) $[*$ (to) oti ehis filus $]$ simeni pola

the-NOM COMP you.have friends-ACC means much

'That you have friends means a lot.'

GREEK

The general structure of a sentential subject construction would be as follows, with a null DP coreferential with the sentential subject following Alrenga (2005) and Lohndal (to appear).

(85) a. [(The fact) that the building collapsed] surprised me.

b. [*(ze) š-ha-binyan karas] hiftia oti

this COMP-the-building collapsed surprise me

'(The fact) That the building collapsed surprised me.'

HEBREW

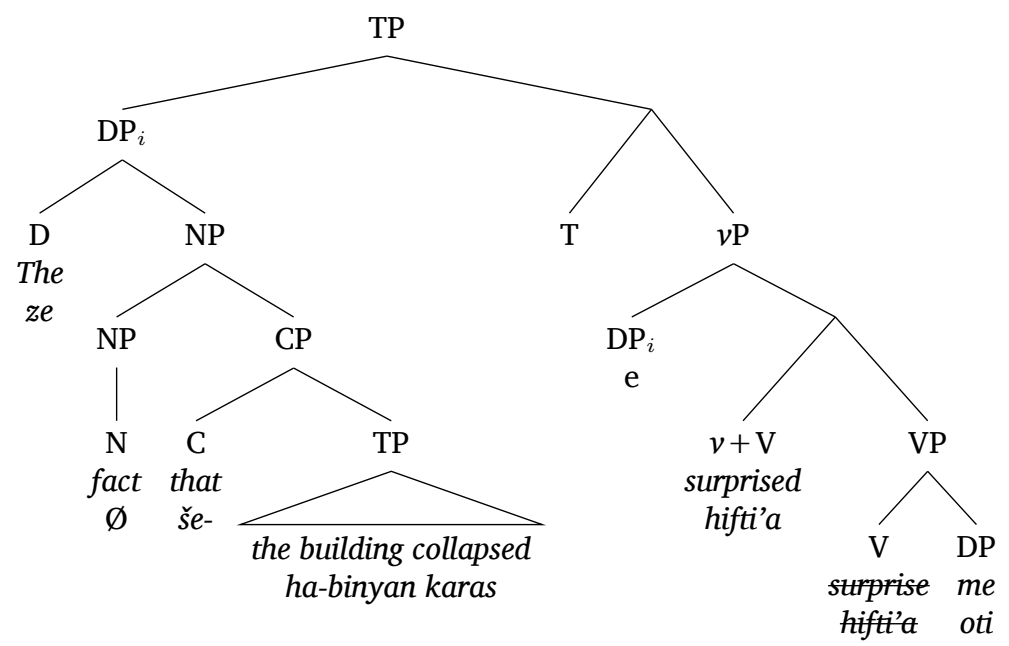

An important assumption here is that the EPP feature is a [D] feature on T (Chomsky 1995). This means that any element merged in the specifier of TP will need to be a DP (but see discussion of the EPP in the Slavic syntax literature, e.g. Bailyn 2004).

To conclude the crosslinguistic angle, some variation between languages ought to be pointed out. In Hebrew, Greek and other languages, the sentential subject must be an Overt Definite Presuppositional. In English, it can be an Overt Definite Presuppositional or an SEP. In yet other languages, such as German, a sentential subject cannot be preceded solely by a D element such as es 'it'. I will assume that in English, a discourse-relevant element in the left periphery licenses $\Delta$ in subject position when the sentential subject is an SEP, (86). 
(86) [That the building collapsed] surprised me.

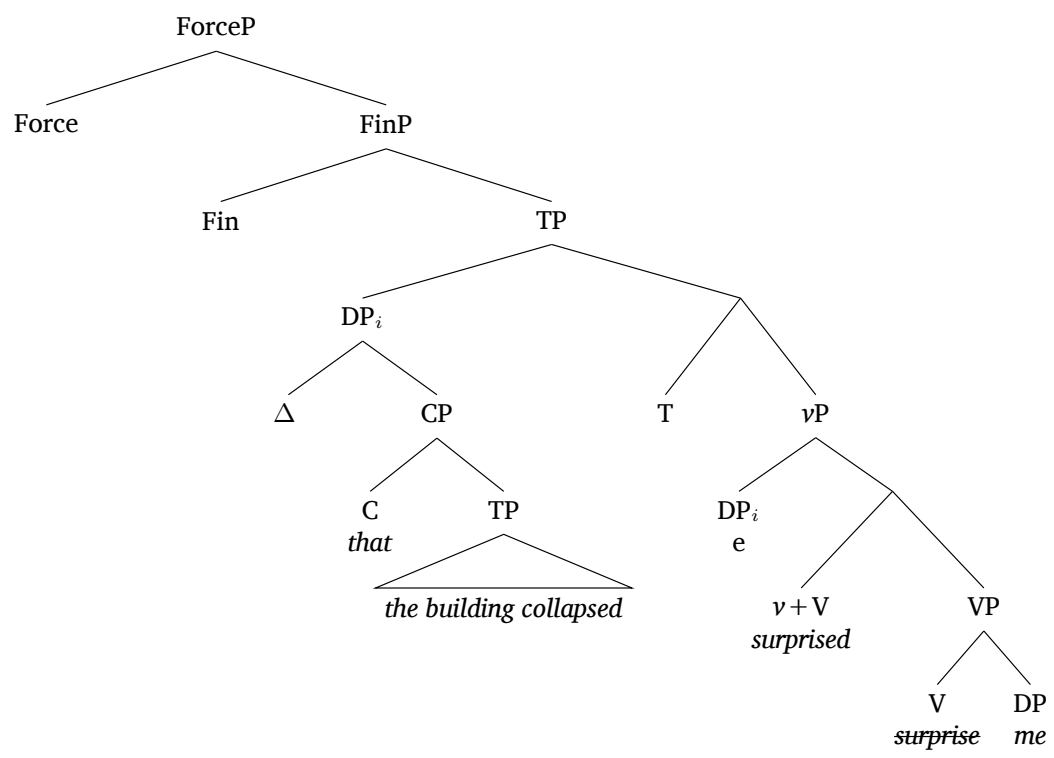

Since a construction with an overt DP subject such as The fact that is always available-and is the only construction available for some languages-I will treat sentential subjects as Overt Definite Presuppositionals for the default case crosslinguistically, while allowing for some languages (like English) to have SEP sentential subjects as well. The overarching theme of factivity and interpretation both fed by the syntax is unaffected.

By treating sentential subjects as Overt Definite Presuppositionals like in (85), we claim that the $\mathrm{CP}$ embedded within is an adjunct. Extraction is not allowed from adjuncts, and hence not allowed from sentential subjects. The Sentential Subject Constraint can now be reduced to the ban on extraction from adjuncts or the Complex NP Constraint, just like with other Overt Definite Presuppositionals. This is a quick and elegant solution for all languages discussed here, other than English.

English also allows sentential subjects without the fact that, as in (86), but the Sentential Subject Constraint bans extraction even from them (Ross 1967). Independent work on subextraction and freezing effects might hold the key here. If the sentential subject raises from Spec, $v \mathrm{P}$ to Spec, TP, then it would be frozen and a constituent embedded in it would not be able to extract (Gallego \& Uriagereka 2006; Müller 2010). This kind analysis is not a new result of our system but is entirely consistent with it.

\subsection{Factivity Mirrors Interpretation}

By now we have established that the sentential subject sitting in the specifier of TP is itself a DP. The theory developed so far predicts presupposition as well as possible factivity and special meaning for definite DPs. Indeed, in a recent commentary Bhatt (2010:176) noted that "certain sentential subjects (but not all) are interpreted factively". His examples are reproduced here:

(87) a. That John is so tall is amazing.

b. \# That John is so tall is false.

c. That John is rich is widely believed by his classmates. (He's managed to fool them all!) 
Which sentential subjects are interpreted factively and which are not? Note that Bhatt spoke of factivity, not presupposition, but it is best to address the presuppositionality of sentential subjects first.

A definite DP is interpreted as a definite description, referring to a discourse referent in the CG. Hence, any definite DP in subject position will be presupposed. The examples in (87) all presuppose that John's tallness or richness are already a topic of conversation. To see whether or not a given sentential subject is factive, we need to check the entailments of the matrix predicate, just like in the case of clausal complements.

As noted before, the status of copular sentences is unclear and I will not pursue them in depth. While Bhatt (2010) judges (88a) as ill-formed, example (88b) is acceptable. ${ }^{23}$

(88) a. \# That John is so tall is false.

b. That John is tall is false/a misconception.

It is possible to find environments in which factivity arises even when the matrix verb is not factive. To see this, we will need to look at cases where a non-presuppositional verb selects a clausal complement which is raised to subject. This is what happens in passives. Let us start with a non-sentential subject construction. As discussed earlier, the semantic difference between a Selected Embedded Non-presuppositional and an Overt Definite Presuppositional is that the latter is factive and may receive a special interpretation. The CP utterance (89a) is non-presuppositional and has the "simple" interpretation, while the DP utterance (89b) is presuppositional and has a special or idiosyncratic interpretation.

(89) a. The Mayor explained [ ${ }_{C P}$ that the building collapsed].

b. The Mayor explained [ ${ }_{D P}$ the fact that the building collapsed].

When the sentences are passivized, our prediction is that the resulting structure has to be a DP in order to merge in Spec,TP, and therefore will be factive and possibly idiosyncratic. This is borne out.

(90) ${ }_{D P}$ That the building collapsed] was explained lapse).

by the mayor (\# but it didn't col-

...The contractor was a crook, the building supplies were bought cheap and safety regulations were flaunted.

Pietroski (2000) and Halpert \& Schueler (2013) reach a similar conclusion, but do not connect the interpretation facts to factivity.

They also do not go beyond explain, but we will. For our next step, we take a number of nonpresuppositional verbs that show different interpretations based on whether their complements are CPs or DPs. Explain is one, and we have seen in the previous section that observe and guess are two more. In all three cases, the passivized versions give rise to factivity and the special reading. This is because the DP was originally merged as such, creating the basic [V DP] structure. Since interpretation is decided based on the relationship with $\mathrm{V}$, then whatever meaning is established inside the VP will persist even if the object is promoted to subject as in (91). In contrast, if we take non-presuppositional verbs which exhibit no difference in interpretation between CP complements and DP complements, the result is non-factive and non-special (92).

\footnotetext{
${ }^{23}$ Utterance (87b) is fine if so tall is replaced by four feet tall:

(i) That John is four feet tall is false.

It is unclear whether the speaker is directly challenging the presupposition here.
} 
(91) Non-presuppositional explain-type verb, factive sentential subject, special meaning.

a. That the building collapsed was explained by the mayor.

b. That the building collapsed was observed by the mayor.

c. That John is the killer was guessed (at) by the fortune teller.

(92) Non-presuppositional verb, non-factive sentential subject, no special meaning.

a. ?That the building collapsed was said by everyone.

b. That the water is safe to drink was reiterated (disingenuously) by the mayor.

c. That this is the right way of analyzing the sentence is thought (wrongly) by many. Whether or not a sentential subject will be factive is thus fully predictable, solving Bhatt's puzzle: if the verb is factive then the sentential subject will be factive (know, remember). That much is self-evident. But if the verb can take DPs or CPs with different interpretations, then it is also predicted to yield factive sentential subjects (with potentially special interpretation).

Further insight is lent by another form of passivization. The impersonal passive allows only the CP-like "say x" reading, not the DP-like "explain why $\mathrm{x}$ " reading:

(93) It was explained by the Mayor that the building collapsed (but he was mistaken).

$\approx$ The mayor said that the building collapsed.

What is the structure of the impersonal passive? A number of researchers have suggested that the expletive it raises to subject position, leaving the embedded clause low. See one such system in Stroik (1996). If this is correct, then embedded clauses as in (93), which appear in a postverbal position, were never subjects to begin with. Such a clause is simply a CP complement of the verb, and as such it receives neither special meaning nor factive interpretation.

The impersonal passive is also able to accommodate verbs like agree or hope, which do not take an "ordinary" DP as a direct object.

(94) a. *John agreed/hoped [ $D P$ the book / lunch].

b. It was agreed/hoped [ $C P$ that they would go to lunch / that they would finish the book].

Once again, this example is incompatible with the lower clause being a DP. These facts provide further fodder for the claim that the impersonal passive is not derived from an underlying active sentence in which a DP object was raised to subject.

An anonymous reviewer suggests a possible prediction made by this theory. If sentential subjects are uniformly DPs, then passivization of examples (65)-(66) from Section 5 should be grammatical. The judgments reported here reflect the overall contrasts from seven native speakers, though there is much variation:

(95) a. ?[Americans should get cheap oil], which is said by the whole world _.

b. ?? [Americans should get cheap oil], which is claimed by the whole world

(96) * This mist can't last, which is claimed by Morpho and Hoppy

I am not sure that this prediction can be tested straightforwardly, however. Which-clauses seldom appear in subject position and do not ordinarily get passivized. There might be independent reasons for the degradedness of these examples. Generally speaking, the syntax of parenthetical movement is not well understood and I must limit myself to pointing out the empirical generalizations. Vicente (2014) has recently attempted to zero in on the semantic type of these gaps, but their syntax is still up for debate. 


\subsection{Sentential Subjects and Raising}

Developing Bhatt's examples some more, we will now examine raising predicates and find that they are presuppositional but non-factive, as is to be expected. The DP-ness of sentential subjects in raising constructions can be further established based on the work of Alrenga (2005:175) and Lohndal (to appear), who discuss the difference between seem and suck. They point out that seem cannot select a DP and cannot take a sentential subject.

(97) a. [The Giants' loss] really sucks/*seems.

b. [That the Giants lost] really sucks/*seems.

What about factivity in raising constructions? We find that no presupposition failure arises when negating a raised sentential subject, although the construction does sound odd to some speakers.

(98)\% That John went to Cambridge \{appears / seems / turned out to be false.

The non-factive reading in (98) makes sense since a raising verb is the kind of verb that can never take a DP complement, and so it will never license a definite, factive DP.

Other predicates are also compatible with our analysis; in (99), unlikely requires its argument, that John is four feet tall, to be non-factive by virtue of its lexical semantics: for something to be unlikely it cannot always be true. The argument is then raised, remaining non-factive but presupposed.

(99) [тр that John is four feet tall [ T [ $\nu_{\mathrm{P}}$ [ seems [sc that John is four feet tall unlikely ]]]] We are left with the non-factive example in (87c) above, repeated here:

(100) That John is rich is widely believed by his classmates. (He's managed to fool them all!)

The sentential subject is non-factive but it is still presuppositional. The issue here is the verb believe, which is incompatible with factivity across the board:

(101)?? Bill believed the fact that John was rich.

(102) Bill believed the rumors.

Utterance (102) is well-formed, but rumors are not facts. Without entering into metaphysics, it seems that believing is not compatible with factivity: if what one believes is a fact, then believing should become knowing. ${ }^{24}$

This talk of passives and raising predicates raises another question, the last one we will consider in this paper: why is the covert DP shell for sentential subjects not available in object position?

\footnotetext{
${ }^{24}$ An exploratory Google search did not turn up any appropriate examples for the string \{believed the fact that within the first 50 results. However, the minimally distinct string \{believe the fact that was relatively common in downward-entailing environments.

(i) Why cant right handed people believe the fact that left handed people are smarter? [http://answers.yahoo. com/question/index?qid=20121106114105AAYwuDm]

(ii) GOP Lawmaker Refuses To Believe The Fact That Rep. Eric Cantor Is Shorting U.S. Treasury Bonds [http: //thinkprogress.org/politics/2011/07/08/263264/olson-cantor-shorting-treasury/]

(iii) I Don't Believe The Fact That Teachers Have Extra Eyes Behind Their Heads [http://www.facebook. com/pages/I-Dont-Believe-The-Fact-That-Teachers-Have-Extra-Eyes-Behind-Their-Heads/ 280518226833]

All examples were retrieved May 2013. I leave further investigation into this phenomenon, if it holds up to further scrutiny, to future work.
} 


\subsection{D and Clausal Complements}

The same question was posed in different ways by a number of authors: if sentential subjects have a silent DP shell, why don't objects? Put otherwise, why is (103a) not a possible DP shell if (103b) is? (Alrenga 2005; Takahashi 2010; Sheehan \& Hinzen 2011; Hartman 2012)

(103) a. *This formulation of the rule captures $\left[_{D P} \mathrm{D}[C P\right.$ that these nouns behave differently]].

b. $\quad\left[{ }_{D P} \mathrm{D}[C P\right.$ That these nouns behave differently] is captured by this formulation of the rule.

The emerging consensus in the literature is that a complement $\mathrm{CP}$ must be made into a DP in one way or another using a "dummy" D before it can become a sentential subject. Hartman (2012:62) calls this a Last Resort principle, for instance, inserting a DP shell post-cyclically. Sheehan \& Hinzen (2011) invoke the Empty Category Principle. Takahashi (2010) uses a more elaborate system, placing an uninterpretable feature on D and an EPP feature on Topic, forcing movement. These are all attempts to address the same question.

But the issue runs deeper. Here is another way of looking at it. Take the examples from (16), repeated here as (104). Why isn't (105) a good structure for (104b)?

(104) a. The President answered [ ${ }_{D P}$ the question].

b. The President answered [ ${ }_{C P}$ that construction will go ahead as planned].

(105) The President answered ${ }_{D P} \Delta\left[\left[_{C P}\right.\right.$ that construction will go ahead as planned]].

(to be rejected)

Haegeman \& Ürögdi (2010a:136) and Moulton (2015) argue, in similar fashion, that presuppositional verbs do not take DP complements because it is not possible to say (106a), only (106b).

(106) a. *I agree $[D P \Delta$ something].

b. I agree to $[D P$ something].

The claim advanced in this paper is that there exist specific licensing requirements between $\mathrm{V}$, $\Delta$ and C. So let us break this down.

In section 4.1 we discussed the contrast between The bartender claimed that I was drunk and *The bartender claimed if I was drunk, and concluded that the embedded clauses are best analyzed as having similar structures, although certain licensing relations do hold between the matrix $\mathrm{V}$ and the embedded elements. The question is, what do verbs like agree license?

(107) Agree's licensing and selectional requirements:

a. Licenses PPs complements (agree to something).

b. Licenses entities (agree to something).

c. Does not license direct object DPs (*agree something).

d. Licenses propositions, but these must then be embedded in entities as in (b).

In other words, agree licenses either a PP complement with an entity in it or $\Delta$ embedding a proposition. Next, what does $\Delta$ license?

(108) $\Delta$ selects for a CP, just like D selects for an NP. It is a nominalizer.

It is possible to find supporting evidence for the notion of fine-grained subcategorization. Sheehan \& Hinzen (2011) discuss interesting cases of COMP-drop: why is that obligatory in the head of a CP in (109)?

(109) Lois \{resents/cares/doesn't mind\} *(that) Superman's dead.

So it turns out that we might need to separate licensing of a specific $\mathrm{C}$ from licensing of $\mathrm{CP}$, and likewise licensing of a specific $\mathrm{D} / \Delta$ from licensing of DP. 
Note that licensing a clause must be different in one way or another from licensing an entity, regardless of the theoretical model employed. If agree really did take a PP and a CP but not a DP, as per Haegeman \& Ürögdi and Moulton, what would the reason be? Some form of selection must be going on, which we happen to model with the determiner $\Delta$ for reasons laid out in the preceding sections. ${ }^{25}$

So far in this section I have attempted to clarify how licensing of $\Delta$ is similar to licensing of other elements. In the remainder, we examine why it is that only some predicates license $\Delta$.

The system we have built makes a prediction regarding the interplay of syntax and semantics for presuppositional verbs. Consider the kinds of events that these are. Response stance verbs (agree, deny, admit, accept) are speech acts, undertaken with regards to a certain proposition. Non-stance verbs (remember, forget, realize, notice) are a kind of psych-verb, denoting an experiencer-internal reaction to a proposition. These verbs denote events in which the subject accesses a filecard and updates it.

On the other hand, there are verbs that entail the creation of a new entity. For example, Diesing (1992:111) points out that verbs like write, draw and paint "denote the bringing of their objects into existence and therefore are incompatible with the notion of preexistence". The same goes for volunteered stance verbs: they bring about the existence of a proposition. It is not possible to produce a drawing and have that exact same drawing already exist. Likewise, it is not possible to utter a novel proposition and have that proposition already exist. But it is possible to refer to an existing proposition.

Technically speaking, verbs like say, think, answer and iterate (on its volunteered stance reading) do not license the presuppositional determiner $\Delta$. Here is an algorithmic view of how to use silent definite determiners.

(110) Attempt to merge a DP headed by $\Delta$ with V. Is the DP with $\Delta$ licensed by V?

a. If so, interpret it as the object. Factivity will be triggered if the verb is factive. Example: The mayor forgot $\Delta$ that construction went ahead as planned (\# but it didn't).

b. You may then raise this DP to subject in order to satisfy the EPP. Example: $\Delta$ That construction went ahead as planned was forgotten by the mayor.

c. If the DP with $\Delta$ is not licensed by $\mathrm{V}$, raise it to subject in order to satisfy the EPP. Example: $\Delta$ That construction went ahead as planned \{was said by the mayor / appears $\overline{\text { to be true }}$.

This returns us to the question of why verbs like capture in (103) do not license $\Delta$. Simply put, capture is not a response stance or a non-stance verb. It patterns together with a number of other verbs of communication (Kuno 1973; Grimshaw 1982; Jacobson 1992; Alrenga 2005; Takahashi 2010):

(111) a. This formulation of the rule \{captures / expresses / reflects / brings out $]_{D P}$ the fact $/ * \mathrm{D}[\mathrm{CP}$ that these nouns behave differently] $]$.

b. Even Aristotle contemplated $\left[D P\right.$ the possibility $/ * \mathrm{D}\left[{ }_{C P}\right.$ that the moon is made of cheese]].

c. We have given $\left[{ }_{D P}\right.$ the possibility/*D $\left[{ }_{C P}\right.$ that Jack is a double agent $]$ serious consideration.

While it is true that these verbs refer to some proposition, they are not speech acts like response stance verbs are, nor are they factive verbs that express a psychological attitude towards a

\footnotetext{
${ }^{25}$ For example, in a more articulated theory of licensing, one might say that agree licenses $\Delta$ but that $\Delta$ does not assign Case, necessitating the preposition to.
} 
proposition. So they are not the kind of verb that licenses $\Delta$.

\subsection{Summary and Overview}

In this section I suggested that sentential subjects are Overt Definite Presuppositionals or Selected Embedded Presuppositionals, thereby accounting for two observations made previously: that they are factive and that they are nominal. This analysis also explains why they are headed by certain determiners crosslinguistically. We also considered putative counterexamples to these generalizations: non-factive sentential subjects, which stem from passivized verbs and raising verbs. The facts all fall into place from our minimal assumptions about the selectional requirements of different predicates.

A [D] feature on T restricts Spec,TP to DPs. This means that every subject is a DP, and accordingly that every sentential subject is a DP. Some sentential subjects are born DPs, some achieve DP-ness, and some have DP-ness thrust onto them. The combination of an object DP with $\mathrm{V}$ may result in special meaning and factivity. If the object is just a CP complement, raising it to subject will force it to be merged as a DP with a silent $\Delta$.

The analyses of selection, extraction, fronting, anaphora, interpretation and sentential subjects are now behind us. Let us briefly revisit the original notion of nominal factivity. The account of factive verbs in Kiparsky \& Kiparsky (1970) posited the existence of a silent FACT heading the embedded clause (112a). Already the Kiparskys themselves noted an immediate problem with this analysis (Kiparsky \& Kiparsky 1970:147ff), which is that even though verbs like know and realize are factive, it is not possible to say (112b). I add that it is also impossible to say (112c). This kind of analysis was also not built to handle the extraction, fronting and interpretation facts presented here.

(112) a. I know FACT that John is here.

b. *I know the fact that John is here.

c. *I know FACT which John is here.

Similar problems hamper Kayne's more recent proposal (Kayne 2008, 2009; see also Arsenijević 2009) which keeps the silent FACT as the head of a relative clause, in a system which attempts to reduce all subordination to relativization.

As the view shifts from seeing factives as full DPs to a different kind of nominalization, data from other languages emerges. Krapova (2010) has proposed an account of factive clauses based on Bulgarian data which resembles our Selected Embedded Presuppositionals to a certain extent. Her account embeds the CP in a DP, but then embeds the latter in an additional PP layer: the structure in her theory involves a $\mathrm{P}$ and a $\mathrm{D}$.

The Bulgarian data are different than the kind surveyed here, though: the embedding predicates in question are not factive but emotive (worry, be sorry, be happy), and the C deto involved is the relativizer rather than the factive complementizer. The cases are not parallel, since the Bulgarian data are about more than presupposition per se. As for the analysis, we do not require a silent embedding $P$ but that does not preclude our structure from being embedded by a silent $\mathrm{P}$ in Bulgarian if necessary, and perhaps in Bulgarian this $\mathrm{P}$ contributes the relative or emotive meanings. ${ }^{26}$ I conclude, then, that it is more accurate to talk about presuppositional clauses than factive clauses and about discourse referents than full DPs.

\footnotetext{
${ }^{26}$ This paper has not addressed Slavic languages; the behavior of elements like čto 'what' and to 'that' in Russian and related languages must be left for further work, though see Progovac (1998) for a possible starting point.
} 


\section{Conclusion}

The novel data in this paper come in three flavors: differences in interpretation of a complement, differences in presupposition and differences in factivity. The syntactic category of the complement is important: presupposition and special interpretation cannot arise unless there is a DP in the structure. The result is that presupposition and interpretation go hand in hand, dictated by the selectional properties of the embedding predicate. This result lends insight to our understanding of argument structure, furthering our knowledge of the kind of arguments different verbs can take.

We started off with the idea that presuppositional verbs do not introduce a new discourse referent but call up an existing one from the conversational Common Ground. Once we model this discourse referent as a definite DP, a range of facts fall into place.

Presuppositional clauses are definite DPs: crosslinguistic data show that they may be headed by an overt $\mathrm{D}$ which is always definite, but never by an indefinite article or a distal demonstrative. The definiteness serves to pick out a salient discourse referent, i.e. a presupposed one. Extraction effects can be viewed in terms of extraction from a weak island (for Selected Embedded Presuppositionals): the creation of a new discourse referent obviates the intervention effect caused by the embedding predicate. Extraction from Overt Definite Presuppositionals is banned because these are strong islands, namely Complex NP/adjunct islands.

Fronting effects are explained by allowing Selected Embedded Presuppositionals to have a reduced left periphery, a technical implementation of the reduced illocutionary force exhibited by presupposed utterances as opposed to assertions. Reduction of the left periphery is made available through selectional relations between the matrix verb, the selected determiner $\Delta$ and the embedded complementizer.

That Selected Embedded Presuppositionals are DPs serves to explain why certain clauses can be referred to using the CP anaphor as and others using the DP anaphor which. The whichclauses are embedded under presuppositional verbs, which select for DPs. The as-clauses are embedded under both presuppositional and non-presuppositional verbs, since both embed CPs.

Generally speaking, clausal complements can be CPs or DPs, depending on the embedding predicate. Different meanings arise depending on the category of the complement, especially for DP complements. These complements can have special, idiosyncratic meaning when merged with the verb, whereas the meaning of CP complements is predictable. In other words, there is a form-meaning isomorphism in which CPs are appositives and DPs are individuals with potentially special meaning.

Sentential subjects have been shown to be DPs crosslinguistically. In some languages they are headed by the same D as embedded factive clauses, a fact that has escaped notice so far. This observation makes sense if sentential subjects are raised to subject position from object position, and if the determiner that precedes a factive clause must be definite. Sentential subjects are presupposed clauses simply by virtue of being subjects, but they might be factive and lead to special meaning depending on the lexical semantics of the matrix predicate. This, too, is expected on a view raising them from object position.

To conclude, the lexical semantics of the matrix predicate interacts directly with $\mathrm{D}$ and the $\mathrm{C} /$ Force head it embeds, accounting for patterns of presupposition, interpretation and polarity. By considering whether a certain predicate selects for a CP or a DP we are able to predict syntactic and semantic effects. Selection for a proposition corresponds to selection for CP, whereas selection for a definite individual corresponds to selection for a definite DP. The crosslinguistic data corroborate the claims made here. The next step would be to delve deeper into the embedded clause and see whether $\mathrm{T}$ is affected by the value of $\mathrm{C}$ (or of the left periphery). In some languages the kind of clause (main or embedded, perfective or imperfective, honorofic or 
non-honorific) seems to correlate with a different form of the verb. For example, in Japanese there are two kinds of complementizers, nominalizer-like complementizers that pattern with determiners and those that pattern with "ordinary" complementizers. The former are factive and appear with verbs in the END FORM, which is the form of the verb in main clauses. The latter are non-factive and appear with verbs in the ADNOMINAL FORM, which is used in relative clauses and nominalizations (Hiraiwa 2010). Our system predicts that the "factive" ones will turn out to be presuppositional and show the same kind of behavior as presuppositional clauses in English, Hebrew and Greek. In Hungarian, differences in factivity and interpretation are often collapsed together, such that one entails the other: perfective prefixes on the matrix verb entail a factive reading for the embedded clause. Granted, the Japanese and Hungarian phenomena may be unrelated. Still, once these data are properly reviewed, we might learn something new about what makes embedded elements "more presupposed" or "more nominal" (cf. Potts 2002; Legate 2010). We have seen here that the two notions are strongly related.

\section{References}

Aboh, Enoch O. 2010. Event operator movement in Factives: Some facts from Gungbe. Theoretical Linguistics 36(2/3). 153-162. 21

Abrusán, Márta. 2011. Presuppositional and negative islands: a semantic account. Natural Language Semantics 19. 257-321. 5, 14, 15

Abrusán, Márta. 2014. Weak Island semantics. Oxford: Oxford University Press. 5, 13, 14, 15

Adams, Marianne. 1985. Government of Empty Subjects in Factive Clausal Complements. Linguistic Inquiry 16(2). 305-313. 5

Adger, David \& Josep Quer. 2001. The Syntax and Semantics of Unselected Embedded Questions. Language 77(1). 107-133. 8, 17, 18, 19

Alrenga, Peter. 2005. A sentential subject asymmetry in English and its implications for complement selection. Syntax 8(3). 175-207. 29, 30, 34, 35, 36

Anagnostopoulou, Elena. 2014. Roots and domains. Theoretical Linguistics 40(3/4). 299-310. 26

Arsenijević, Boban. 2009. Clausal complementation as relativization. Lingua 119. 39-50. 37

Asher, Nicholas. 1993. Reference to abstract objects in discourse. Dordrecht: Kluwer. 8

Bailyn, John. 2004. Generalized Inversion. Natural Language and Linguistic Theory 22(1). 1-50. 30

Barker, Chris. 2013. Scopability and sluicing. Linguistics and Philosophy 36(3). 187-223. 15

Basse, Galen. 2008. Factive Complements as Defective Phases. In Natasha Abner \& Jason Bishop (eds.), Proceedings of the 27th West Coast Conference on Formal Linguistics (WCCFL 27), 54-62. Somerville, MA: Cascadilla Proceedings Project. 11, 17, 19, 21

Beaver, David. 2010. Have you noticed that your belly button lint colour is related to the colour of your clothing? In Rainer Bäuerle, Uwe Reyle \& Thomas Ede Zimmermann (eds.), Presuppositions and discourse: Essays offered to Hans Kamp, 65-99. Emerald. 5

Bentzen, Kristine. 2010. Exploring embedded main clause phenomena: The irrelevance of factivity and some challenges from V2 languages. Theoretical Linguistics 36(2/3). 163-172. 17

Bhatt, Rajesh. 2010. Comments on "Referential CPs and DPs: An operator movement account". Theoretical Linguistics 36(2/3). 173-177. 21, 22, 31, 32, 33, 34

Cattell, Ray. 1978. On the source of interrogative adverbs. Language 54. 61-77. 4, 5

Chomsky, Noam. 1957. Syntactic Structures. The Hague: Mouton. 23 
Chomsky, Noam. 1986. Barriers. Cambridge, MA: MIT Press. 21

Chomsky, Noam. 1995. The minimalist program. Cambridge, MA: MIT Press. 30

Clark, Herbert H. \& Susan E. Haviland. 1977. Comprehension and the given-new contract. In Roy O. Freedle (ed.), Discourse Production and Comprehension, 1-40. Norwood, NJ: Ablex Publishing Corporation. 29

de Cuba, Carlos. 2007. On (non)factivity, clausal complementation and the CP-field. Stony Brook, NY: SUNY Stony Brook dissertation. 19, 21

de Cuba, Carlos \& Barbara Ürögdi. 2009. Eliminating factivity from syntax: Sentential complements in Hungarian. In Marcel den Dikken \& Robert M. Vago (eds.), Approaches to Hungarian, 29-64. Amsterdam and New York: John Benjamins. 3, 21

de Cuba, Carlos \& Barbara Ürögdi. 2010. Clearing up the 'Facts' on complementation. In University of Pennsylvania working papers in linguistics, vol. 16 1, 41-50. 19

Culicover, Peter W. 1993. Evidence against ECP accounts of the that-t effect. Linguistic Inquiry 24. 557-561. 11

Davies, William \& Stanley Dubinsky. 2009. On the existence (and distribution) of sentential subjects. In Donna B. Gerdts, John C. Moore \& Maria Polinsky (eds.), Hypothesis A / hypothesis $B$ : Linguistic explorations in honor of David M. Perlmutter, 111-128. Cambridge, MA: MIT Press. 29

Dekker, Paul. 1993. Existential Disclosure. Linguistics and Philosophy 16. 561-587. 13

Delahunty, Gerald. 1983. But sentential subjects do exist. Linguistic Analysis 12(4). 379-398. 29

Diesing, Molly. 1992. Indefinites (Linguistic Inquiry Monographs 20). Cambridge, MA: MIT Press. 29, 36

Doron, Edit. 1983. Verbless predicates in Hebrew. Austin, TX: University of Texas dissertation. 12

Emonds, Joseph. 1970. Root and structure-preserving transformations. Cambridge, MA: Massachusetts Institue of Technology dissertation. 17

Farudi, Annahita. 2007. An antisymmetric approach to Persian clausal complements. Ms., UMass Amherst. 6, 27

Fox, Danny. 1999. Reconstruction, binding theory, and the interpretation of chains. Linguistic Inquiry 30. 157-196. 9

Gallego, Ángel J. \& Juan Uriagereka. 2006. Sub-extraction from subjects. Ms., Universitat Autónoma de Barcelona and University of Maryland. 31

Giannakidou, Anastasia. 1998. Polarity sensitivity as (non)veridical dependency. Amsterdam/Philadelphia: John Benjamins. 4, 12

Giannakidou, Anastasia. 1999. Affective Dependencies. Linguistics and Philosophy 22. 367-421. 4

Giannakidou, Anastasia. 2001. The meaning of free choice. Linguistics and Philosophy 24. 659-735. 4

Ginzburg, Jonathan. 1995. Resolving questions I/II. Linguistics and Philosophy 18. 459-609. 18

Green, Georgia. 1976. Main clause phenomena in subordinate clauses. Language 52. 382-97. 17

Grimshaw, Jane. 1979. Complement Selection and the Lexicon. Linguistic Inquiry 10(2). 279326. 2,26

Grimshaw, Jane. 1981. Form, Function and the Language Acquisition Device. In C. L. Baker \& John J. McCarthy (eds.), The Logical Problem of Language Acquisition, 165-182. Cambridge, MA: MIT Press. 8, 26 
Grimshaw, Jane. 1982. Subcategorization and grammatical relations. In Annie Zaenen (ed.), Subjects and other subjects: Proceedings of the Harvard Conference on the Representation of Grammatical Relations, 35-55. Bloomington, IN: Indiana University Linguistics Club. 36

Groenendijk, Jeroen \& Martin Stokhof. 1989. Dynamic Montague Grammar: A First Sketch. Ms., University of Amsterdam. 14

Groenendijk, Jeroen \& Martin Stokhof. 1991. Dynamic Predicate Logic. Linguistics and Philosophy 14. 39-100. 14

Guéron, Jacqueline. 1980. On the Syntax and Semantics of PP Extraposition. Linguistic Inquiry 11(4). 637-678. 29

Haegeman, Liliane. 2010. The internal syntax of averbial clauses. Lingua 120(3). 628-648. 22 Haegeman, Liliane. 2012. The syntax of MCP: Deriving the truncation account. In Lobke Aelbrecht, Liliane Haegeman \& Rachel Nye (eds.), Main clause phenomena: New horizons, 113-134. Amsterdam: Benjamins. 17

Haegeman, Liliane. 2014. Locality and the distribution of main clause phenomena. In Enoch O. Aboh, Maria Teresa Guasti \& Ian Roberts (eds.), Locality, Oxford: Oxford University Press. Ms., Ghent University/FWO. 22, 29

Haegeman, Liliane \& Barbara Ürögdi. 2010a. Referential CPs and DPs: An operator movement account. Theoretical Linguistics 36(2/3). 111-152. 3, 5, 11, 17, 19, 20, 21, 35, 36

Haegeman, Liliane \& Barbara Ürögdi. 2010b. Reply: Operator movement, referentiality and intervention. Theoretical Linguistics 36(2/3). 233-246. 22

Halpert, Claire \& David Schueler. 2013. That sentential subjects are (linked to) DPs is explained herein. Snippets 28. 3, 27, 32

Harley, Heidi. 2014a. On the Identity of Roots. Theoretical Linguistics 40(3/4). 225-276. 26

Harley, Heidi. 2014b. Reply to commentaries, "on the identity of roots". Theoretical Linguistics 40(3/4). 447-474. 26

Hartman, Jeremy. 2012. Varieties of Clausal Complementation. Cambridge, MA: Massachusetts Institute of Technology dissertation. 5, 9, 29, 35

Hegarty, Michael. 1990. On adjunct extraction from complements. In L.L.S. Cheng \& H. Demirdash (eds.), MIT Working Papers in Linguistics, vol. 13, 101-124. 4, 5, 11

Heim, Irene. 1982. The semantics of definite and indefinite noun phrases: University of Massachusetts, Amherst dissertation. 2, 6

Heim, Irene. 1983. File change semantics and the familiarity theory of definiteness. In R. Bäuerle, C. Schwarze \& A. von Stechow (eds.), Meaning, use and interpretation of language, 164-189. Berlin: De Gruyter. 2, 6

Heim, Irene. 1992. Presupposition projection and the semantics of attitude verbs. Journal of Semantics 9. 183-221. 14

Heycock, Caroline. 2006. Embedded Root Phenomena. In Martin Everaert \& Henk van Riemsdijk (eds.), The Blackwell Companion to Syntax, vol. 2, 174-209. Blackwell. 17

Higgins, F. R. 1972. The pseudocleft construction in English. Cambridge, MA: Massachusetts Institute of Technology dissertation. 25

Hiraiwa, Ken. 2010. Complement types and the CP/DP parallelism - A case of Japanese. Theoretical Linguistics 36(2/3). 189-198. 39

Hofmeister, Philip \& Ivan Sag. 2010. Cognitive Constraints and Island Effects. Language 86. 366-415. 12

Honcoop, Martin. 1998. Dynamic excursions on weak islands: University of Leiden dissertation. $2,7,13,14,15,25$

Hooper, Joan \& Sandra Thompson. 1973. On the Applicability of Root Transformations. Linguistic Inquiry 4. 465-497. 4, 17, 19 
Huang, C.-T. James. 1982. Logical relations in Chinese and the theory of grammar. Cambridge, MA: Massachusetts Institute of Technology dissertation. 12

Irwin, Patricia. 2012. Unaccusativity at the Interfaces: New York University dissertation. 14, 29 Jacobson, Pauline. 1992. The lexical entailment theory of control and the tough-construction. In Ivan Sag \& Anna Szabolcsi (eds.), Lexical Matters, 269-299. Stanford, CA: CSLI Publications. 36

Jiménez-Fernández, Ángel \& Shigeru Miyagawa. 2014. A feature-inheritance approach to root phenomena and parametric variation. Lingua 145. 276-302. 17, 22

Kallulli, Dalina. 2010. Belief will create fact: On the relation between givenness and presupposition, and other remarks. Theoretical Linguistics 36(2/3). 199-208. 21, 22

Kandybowicz, Jason. 2006. Comp-trace effects explained away. In Donald Baumer, David Montero \& Michael Scanlon (eds.), Proceedings of the 25th West Coast Conference on Formal Linguistics (WCCFL 25), 220-228. Somerville, MA: Cascadilla Press. 11

Kastner, Itamar \& Kathryn Davidson. 2013. Nominalizing Clauses: Evidence from ASL and a New Typology of Embedding. In Theoretical Issues in Sign Language Research (TISLR) 11, London. 6

Kayne, Richard S. 2008. Antisymmetry and the Lexicon. Linguistic Variation Yearbook 8(1). 1-31. 6, 37

Kayne, Richard S. 2009. Why isn't This a complementizer? In Peter Svenonius (ed.), Functional Structure from Top to Toe: A Festschrift for Tarald Taraldsen, . 37

Kempson, Ruth. 1975. Presupposition and the Delimitation of Semantics. Cambridge: Cambridge University Press. 9

Kiparsky, Paul \& Carol Kiparsky. 1970. Fact. In M. Bierwisch \& K.E. Heidolph (eds.), Progress in Linguistics, 143-173. The Hague: Mouton. 2, 4, 6, 23, 37

Kluender, Robert \& Marta Kutas. 1993. Subjacency as a Processing Phenomenon. Language and Cognitive Processes 8(4). 573-633. 11

Koster, Jan. 1978. Why subject sentences don't exist. In Samuel Jay Keyser (ed.), Recent transformational studies in European languages, 53-64. Cambridge, MA: MIT Press. 29

Krapova, Iliana. 2010. Bulgarian relative and factive clauses with the invariant complementizer deto 'that'. Lingua 120. 1240-1272. 37

Kratzer, Angelika. 1996. Severing the External Argument from its Verb. In J. Rooryck \& L. Zaring (eds.), Phrase Structure and the Lexicon, 109-137. Dordrecht: Kluwer. 26

Kuno, Susumu. 1973. Constraints on internal clauses and sentential subjects. Linguistic Inquiry 4. $363-385.36$

Kuno, Susumu. 2004. Empathy and direct discourse perspectives. In Laurence R Horn \& Gregory Ward (eds.), The handbook of pragmatics, 315-343. Oxford: Blackwell. 9

Lebeaux, David. 1988. Language acquisition and the form of grammar: University of Massachusetts Amherst dissertation. 9

Lees, Robert. 1960. The grammar of English nominalizations. The Hague: Mouton. 29

Legate, Julie Anne. 2010. On how how is used instead of that. Natural Language and Linguistic Theory 28. 121-134. 39

Lewis, David. 1979. Scorekeeping in a language game. Journal of Philosophical Logic 8. 339359. 6

Lipták, Anikó. 2010. On event operator movement in English factives. Theoretical Linguistics 36(2/3). 225-231. 21

Lohndal, Terje. 2013. Sentential subjects: topics or real subjects? In Proceedings of the 31st West Coast Conference on Formal Linguistics (WCCFL 31), Cascadilla, MA: Cascadilla Proceedings Project. 29 
Lohndal, Terje. to appear. Sentential subjects in English and Norwegian. Syntaxe et Sémantique . 29, 30, 34

Maki, Hideki, Lizanne Kaiser \& Masao Ochi. 1999. Embedded topicalization in English and Japanese. Lingua 109(1). 1-14. 17

Marantz, Alec. 1984. On the Nature of Grammatical Relations (Linguistic Inquiry Monographs 10). Cambridge, MA: MIT Press. 26

Melvold, Janis. 1991. Factivity and definiteness. In MIT Working Papers in Linguistics, vol. 15, 97-117. 4, 9, 11

Merchant, Jason. 2001. The syntax of silence: sluicing, islands, and the theory of ellipsis. Oxford: Oxford University Press. 15

Miyagawa, Shigeru. 2010. Why Agree? Why Move? Unifying agreement-based and discourseconfigurational languages (Linguistic Inquiry Monographs 54). Cambridge, MA: MIT Press. 22

Moulton, Keir. 2009. Natural Selection and the Syntax of Clausal Complementation: University of Massachusetts Amherst dissertation. 23, 25

Moulton, Keir. 2012. Clause Positions. Ms., UCLA. lingbuzz/001488. 27

Moulton, Keir. 2013. Not Moving Clauses: Connectivity in Clausal Arguments. Syntax 16(3). 250-291. 9, 26, 27, 28

Moulton, Keir. 2015. CPs: Copies and compositionality. Linguistic Inquiry 46(2). 305-342. 9, 23, 35, 36

Müller, Gereon. 2010. On Deriving CED Effects from the PIC. Linguistic Inquiry 41(1). 35-82. 12,31

Odijk, Jan. 1997. C-Selection and S-Selection. Linguistic Inquiry 28(2). 365-371. 26

Oshima, David Y. 2007. On factive islands: Pragmatic anomaly vs. pragmatic infelicity. In Takashi Washio, Ken Satoh, Hideaki Takeda \& Akihiro Inokuchi (eds.), New frontiers in artificial intelligence, vol. 4384 Lecture Notes in Computer Science, 147-161. Berlin: Springer. 22

Pelletier, Francis Jeffry \& Lenhart Schubert. 1989/2003. Mass expressions. In F. Guenthner \& D. Gabbay (eds.), Handbook of philosophical logic, vol. 10, 249-336. Dordrecht: Kluwer 2nd edn. 8

Pesetsky, David. 1982. Paths and Categories. Cambridge, MA: Massachusetts Institute of Technology dissertation. 26

Pesetsky, David. 1992. Zero syntax. Volume 2: Infinitives. Ms., Massachusetts Institute of Technology. 26

Pesetsky, David. 1993. Topic ... Comment. Natural Language and Linguistic Theory 11. 557-558. 26

Pietroski, Paul. 2000. On explaining that. Journal of Philosophy 97. 655-662. 3, 27, 28, 32

Postal, Paul. 1994. Parasitic and pseudoparasitic gaps. Linguistic Inquiry 25. 63-117. 23, 24

Potts, Christopher. 2002. The Lexical Semantics of Parenthetical-as and Appositive-which. Syntax 5(1). 55-88. 3, 23, 24, 39

Prince, Ellen F. 1981. Toward a taxonomy of given-new information. In Peter Cole (ed.), Radical pragmatics, 223-256. New York: Academic Press. 29

Progovac, Ljiljana. 1998. Event pronominal to. Journal of Slavic Linguistics 6(1). 3-40. 37

Rizzi, Luigi. 1990. Relativized Minimality. Cambridge, MA: MIT Press. 21

Rizzi, Luigi. 1997. The Fine Structure of the Left Periphery. In Liliane Haegeman (ed.), Elements of Grammar, 281-337. Dordrecht: Kluwer. 19

Rizzi, Luigi. 2004. Locality and left periphery. In Adriana Belletti (ed.), Structures and Beyond. The Cartography of Syntactic Structures, 223-251. Oxford: Oxford University Press. 21 
Roberts, Craige. 1989. Modal subordination and pronominal anaphora in discourse. Linguistics and Philosophy 12(6). 683-721. 14

Rooryck, Johan. 1992. Negative and factive islands revisited. Journal of Linguistics 28(2). 343-374. 5

Rosenbaum, Peter. 1967. The grammar of English predicate complement constructions. Cambridge, MA: MIT Press. 3, 29

Ross, John Robert. 1967. Constraints on Variables in Syntax. Cambridge, MA: Massachusetts Institute of Technology dissertation. 3, 12, 16, 25, 29, 31

Ross, John Robert. 1984. Inner islands. In C. Brugman \& M. Macauly (eds.), Proceedings of the tenth annual meeting of the Berkeley Linguistics Society, 258-265. Berkeley, California: Berkeley Linguistics Society. 3, 23

Rothstein, Susan. 1992. Case and NP Licensing. Natural Language and Linguistic Theory 10. 119-139. 26

Roussou, Anna. 1992. Factive Complements and Wh-Movement in Modern Greek. UCL Working Papers in Linguistics 4. 123-147. 6, 12

Roussou, Anna. 2010. Selecting complementizers. Lingua 120. 582-603. 12

Sag, Ivan A., Gerald Gazdar, Thomas Wasow \& Steven Weisler. 1985. Coordination and how to distinguish categories. Natural Language and Linguistic Theory 3. 117-171. 23

Sheehan, Michelle \& Wolfram Hinzen. 2011. Moving towards the edge. Linguistic Analysis 37(3-4). 405-458. 4, 5, 9, 10, 35

Shlonsky, Ur. 1988. Complementizer-cliticization in Hebrew and the Empty Category Principle. Natural Language and Linguistic Theory 6. 191-205. 12

Shlonsky, Ur. 2004. The Form of Semitic Noun Phrases. Lingua 114(12). 1465-1526. 9

Shlonsky, Ur. 2010. Null subjects and topicalization in Hebrew. In The workshop on cartography, kanda university, . 17

Simons, Mandy. 2007. Observations on embedding verbs, evidentiality, and presupposition. Lingua 117. 1034-1056. 4, 5

Spector, Ilona. 2012. It's Hebrew clefts that this paper is about. In Proceedings of ConSOLE XIX, 309-330. 20

Stalnaker, Robert. 1973. Presuppositions. Journal of Philosophical Logic 2. 447-457. 6

Stalnaker, Robert. 1974. Pragmatic presuppositions. In Milton K. Munitz \& Peter K. Unger (eds.), Semantics and philosophy, New York, NY: New York University Press. 6

Stowell, Timothy. 1981. Origins of Phrase Structure. Cambridge, MA: Massachusetts Institute of Technology dissertation. 25

Stowell, Timothy. 1987. As so not so as. Ms., University of California, Los Angeles. 23

Stroik, Thomas S. 1996. Extraposition and expletive-movement: A minimalist account. Lingua 99(4). 237-251. 33

Szabolcsi, Anna. 2006. Strong and weak islands. In Martin Everaert \& Henk van Riemsdijk (eds.), The Blackwell Companion to Syntax, vol. IV, 479-551. Blackwell. 13

Szabolcsi, Anna \& Marcel den Dikken. 1999. Islands. GLOT International . 12, 13

Szabolcsi, Anna \& Frans Zwarts. 1993. Weak islands and an algebraic semantics of scope taking. Natural Language Semantics 1. 235-284. 13

Takahashi, Shoichi. 2010. The hidden side of clausal complements. Natural Language and Linguistic Theory 28. 343-380. 9, 27, 29, 35, 36

Vicente, Luis. 2014. Expanding the typology of parenthetical as-clauses. Ms., Universität Potsdam. 33

Zubizarreta, Maria Luisa. 1982. Theoretical Implications of Subject Extraction in Portuguese. The Linguistic Review 2. 79-96. 5 